\title{
THE NUCLEAR PATTERN OF THE NON-TECTAI, PORTIONS OF THE MIDBRAIN AND ISTHMUS IN PRIMATES
}

\author{
ELIZABETH C. CROSBY AND RUSSELL T. WOODBURNE \\ Department of Anatomy, University of Michigan \\ FOURTEEN PLATES (TWENTY-THREe FIGURES)
}

\section{INTRODUCTION}

The various nuclear groups in the midbrain of primates show marked resemblances to their homologues in subprimate forms, although certain regions are characterized by a marked increase and others by a definite decrease in development. The literature dealing with special regions is considerable in amount and some of it is of relatively early date. That pertinent to the present consideration of these regions has been reviewed under the account of the general literature placed at the end of this series of papers. Attention is called here to a few contributions that have been particularly helpful in the preparation of the primate descriptions. Among such are the studies of Ziehen on various regions of the midbrain, particularly his account of the periventricular regions, and the descriptive analysis of Ingram and Ranson ('35) of the nucleus of Darkschewitsch and the interstitial nucleus of the medial longitudinal fasciculus, which confirmed Stengel's ('24) earlier account. There are innumerable figures and descriptions of various parts of the oculomotor and trochlear gray in primates. Among these may be mentioned the work of Panegrossi ('04), Ramón y Cajal ('11), Brouwer ('18, and elsewhere), Le Gros Clark ('26) and Mingazzini ('28). The differences in nomenclature with respect to the periventricular gray of caudal midbrain and isthmus regions are indicated 
to some extent on the figures of the human brain as well as considered in the general literature. The most recent contribution on the nucleus of the mesencephalic root of $\mathrm{V}$ is that of Pearson ('43) which deals with it in relation to the development of the trochlear nerve of man.

Of the midtegmental regions of the midbrain the red nucleus has received the most attention from investigators. Among those who have considered its nuclear pattern max be mentioned Friedemann ('12), Foix and Nicolesco ('25) and Mingazzini ('28). These observers, and many others, have also considered the substantia nigra in primates. Attention is called to the very beautiful illustrations in the text of Foix and Nicolesco ('25).

The material used in this study of primate midbrain and isthmus consists of two series of the macaque (Macaca mulatta) and two of the human brain. This material was serially cut and stained with toluidin blue following the special Huber fixation. The macaque series were cut at $25 \mu$ and the human at $30 \mu$.

\section{PART I. THE MONKEY}

THE PERIVENTRICULAR GROUPS

\section{General areas of periventricular gray}

As usual, the central gray is divisible into dorsal, lateral and ventral portions. Its dorsal part extends from levels through the posterior commissure rostrally to planes passing through the inferior colliculus, where it is continuous with the chief nucleus of this tectal gray. It is distinctly a tectal structure and as such need not receive further consideration here.

The rostral end of the lateral portion of the periventricular area is in direct continuity with the midline gray of the diencephalon. Caudally it is continuous with the chief nucleus of the inferior colliculus, and so has disappeared in planes through-the anterior medullary velum. Throughout its forward extent it is undifferentiated except in planes of the posterior commissure, where the central subcommissural part of the nucleus of the commissure appears to be derived from it. 
The ventral portion of the central gray, like the lateral portion, is in continuity with diencephalic areas, but, in this instance, with the region medial to zona incerta, and consequently ventral to the potential sulcus limitans (figs. 2 and 3 ). Caudalward the ventral part is continuous with the periventricular gray of the pons (fig. 14). Within this ventral portion lie practically all of the differentiated nuclei of the periventricular gray. Among such differentiated masses, in addition to the eye-muscle nuclei, are, rostrocaudally: the nucleus of Darkschewitsch, the dorsal nucleus of the raphé, the laterodorsal tegmental nucleus and the dorsal tegmental nucleus. At all levels through the midbrain, as is evident from the figures, undifferentiated ventral periventricular gray is to be found in association with these specific nuclei.

\section{Nuclear groups associated with posterior commissure}

The nucleus of the posterior commissure lies over the rostral surface of the fiber complex. The decussating fibers separate the gray mass into lateral and medial portions. The medial part, pars centralis subcommissuralis, consists of a fairly small group of more closely arranged neurons, a derivative of pars lateralis of the periventricular gray (fig. 5). A more externally placed cluster of cells, intercalated along the course of the commissural fibers, but not at first forming any considerable cell mass lateral to them, represents the rostral end of the magnocellular portion of the nucleus of the posterior commissure (fig. 5). Slightly farther caudalward the medial portion becomes indistinguishable from the central gray surrounding it. The lateral part accumulates at the ventrolateral tip of the commissure (fig. 6), being continuous dorsomedially with the intracommissural portion of the nucleus and, as the caudal limits of the fibers are reached, swings over the back of the commissure to pass, without demarcation, into the tegmental gray.

The intracommissural part of the nucleus of the posterior commissure (fig. 5) is poorly developed in the monkey, having representation only in rows of cells, usually one cell thick, intercalated among the commissural fibers as these latter spread ventrolaterally. There is no line of separation between it and the magnocellular part of the nucleus of the commissure. The intracommissural nucleus never extends into the midline, in which respects its relations differ from that of the corresponding gray in many other mammals.

\section{Nucleus of Darkschewitsch}

The nucleus of Darkschewitsch (figs. 4 to 6), present in planes through the Edinger-Westphal nucleus and the rostral end of the 
chief oculomotor complex, lies in the ventral part of the periventricular gray, dorsomedial to the interstitial nucleus of the medial longitudinal fasciculus. This relation to the oculomotor nuclear group represents an increase in size and forward extension of the nuclear masses associated with the oculomotor nerve, rather than a caudal migration or increased size of the nucleus of Darkschewitsch. This latter nucleus is composed of small to medium-sized, multipolar, deeply staining neurons, rather sparsely arranged in relation to fiber fascicles. In its midportion it is nearly oval in outline, but narrows down toward either pole. Its rostral and caudal limits are somewhat difficult to define exactly but it has a length of approximately $\frac{3}{4} \mathrm{~mm}$.

\section{Eye-muscle nuclei}

Oculomotor complex. The chief oculomotor gray is secondarily divisible into three major groups : a ventromedial oculomotor nucleus, a dorsolateral oculomotor nucleus and a caudocentral oculomotor nucleus.

The ventral part of the ventromedial oculomotor nucleus (figs. 4 to 9) makes its appearance rostrally in transverse planes through the transition between the magnocellular and parvocellular parts of the red nucleus. It is ventral to the Edinger-Westphal nucleus. At such levels (fig. 4) it is a relatively discrete, round to oval mass of typical somatic efferent neurons. Followed caudally it elongates but is soon capped by the dorsolateral oculomotor nucleus. It becomes somewhat irregular in outline along its lateral border and cells extend from it into the adjacent medial longitudinal fasciculus (fig. 5). At such planes it becomes separated from the dorsolateral oculomotor nucleus by the small dorsal part of the ventromedial oculomotor nucleus. The dorsal and ventral portions of this ventromedial nucleus gradually become incorporated into a single mass with marked extensions, as rows and clusters of cells, into the medial longitudinal fasciculus (fig. 6). This relationship is associated with a gradual reduction in the ventralmost portions of the common ventromedial group, so that the nucleus assumes again an oval outline except for its lateral extensions into the fasciculus (fig. 6). Behind this plane it becomes continuous with the dorsolateral oculomotor nucleus (figs. 7 and 8). At occasional levels, as it is followed caudalward, the ventromedial nucleus shows a tendency to divide secondarily into medial and lateral parts (figs. 8 and 9), although such division is not constant, and the lateral part maintains an intimate relation, as was noted above, to the caudal end of the dorsolateral nucleus, forming thus a band of cells over the top of the fasciculus. This band, which is replaced by the trochlear nucleus, is continuous, in the macaque, with both the dorsolateral and 
ventromedial oculomotor nuclei. The medial part of the ventromedial oculomotor nucleus continues to planes through the rostral end of the trochlear nucleus (fig. 9), lying dorsomedial but separate from this trochlear gray (unlabelled), and thereafter soon fuses with it.

There is no actual central nucleus of Perlia in the macaque. There are slight indications, caudal to the plane of the Edinger-Westphal nucleus, of a fusion of the ventromedial nuclei of the two sides, as Brouwer ('18) described, but such a fusion is not marked (figs. 7 and 8). The separation of the ventromedial nucleus into medial and lateral portions might suggest a tendency toward an approximation of the two sides and foreshadow a median nucleus of Perlia.

The dorsolateral oculomotor nucleus (figs. 5 to 8 ) appears behind the rostral pole of the ventromedial oculomotor nucleus and dorsal to it, and overlaps the front end of the trochlear nucleus caudally. Rostrally it is medial to the dorsal part of the medial longitudinal fasciculus (figs. 5 to 7 ) but gradually shifts to a position dorsomedial to that bundle (fig. 8). Its caudal pole is dorsal to the lateral part of the fasciculus but separated from this fiber bundle by the lateral part of the ventromedial oculomotor nucleus, with which the dorsolateral oculomotor nucleus is continuous (fig. 8).

The eaudal central nucleus (fig. 9) appears in planes through the caudal third of the oculomotor gray. It lies in the midline region of the central gray, dorsal to the oculomotor complex, which is largely although not exclusively represented by the ventromedial oculomotor nucleus at this level. At first the caudal central nucleus consists only of scattered neurons, but these soon increase in number as the mass is followed rostrocaudalward, and the cell group takes on a shieldlike outline, which is especially well marked in planes through the rostral tip of the trochlear nucleus and thereafter almost immediately disappears. Panegrossi ('04) described a dorsocentral posterior oculomotor nucleus which may be the same as the caudal central nucleus just considered (see also Le Gros Clark, '26). The original paper of Panegrossi is not available and the nucleus figured by Mingazzini ('28) is not the same.

The rostral Edinger-Westphal nucleus appears (fig. 3) in the series in planes which cut the habenular nucleus dorsally and the cerebral peduncle ventrally, passing through in course the parvocellular portion of the red nucleus. Thus it lies close to the diencephalicmesencephalic boundary. It is paired, each nucleus lying near the midline, ventral to the ventricle and medial to the medial longitudinal fasciculus (fig. 3). This rostral portion passes over into the caudal Edinger-Westphal nucleus without clear separation. The caudal Edinger-Westphal complex lies dorsal to the ventral part of the ventromedial oculomotor nucleus (fig. 4). At such planes the caudal Edinger- 
Westphal nuclei are paired, but the nuclei of the two sides lie very close together. Still farther caudalward, the caudal nuclei begin to decrease in size and their ventral tips disappear, the remaining dorsal portions overriding the dorsolateral oculomotor nuclei for a short distance (fig. 5). Both the rostral and the caudal EdingerWestphal nuclei consist of medium-sized, stellate to spindle-shaped multipolar neurons with Nissl granules resembling those seen in preganglionic neurons. Even in toluidin blue preparations, at favorable levels, processes of these cells can be traced into the beginning of the oculomotor roots.

Trochlear gray. The trochlear nucleus (figs. 10 and 11) indents the dorsal surface of the medial longitudinal fasciculus. Rostrally it is continuous with the band of oculomotor gray which represents ventromedially the caudal tip of the ventromedial oculomotor nucleus and laterally and dorsolaterally the caudal tip of the dorsolateral oculomotor nucleus (see description of these nuclei). The trochlear nucleus is almost circular in cross section (fig. 10) except at its extremes. It is eigar-shaped to columnar in longitudinal sections. The macaque has an unusually large trochlear nucleus with root fibers that are correspondingly conspicuous. Its neurons resemble very closely those constituting the oculomotor gray with which it is continuous.

\section{Dorsal nucleus of raphé}

The dorsal nucleus of the raphé begins rostrally in planes through the caudal central oculomotor nucleus. It lies dorsal to this nucleus and is represented by small to medium-sized, deeply staining cells scattered across the midline (fig. 9). Followed caudally these cells increase in number to form a central portion and lateral wings (fig. 10) although the mass is not distinctly organized or sharply delimited. Caudally in planes still through the trochlear nucleus the medial portion of the dorsal nucleus of the raphé, and particularly its more ventral part, becomes very indistinct and then the central mass disappears. The lateral portions extend outward and ventrally toward the edge of the central gray forming a supratrochlear mass (fig. 10) and, behind the plane of the trochlear nucleus (fig. 11), form columns on either side of the midline. Still farther caudalward, at levels through the laterodorsal tegmental nucleus, these lateral wings of the dorsal nucleus of the raphe are reduced ventrally and rise slightly dorsally, so that, toward their caudal extreme, they form a mass of slightly larger cells invading the ventral eminence on the ventricular floor (fig. 12). Although this nucleus has a long rostrocaudal extent, its looser arrangement renders it less sharply differentiable than in many other forms. 


\section{Laterodorsal tegmental nucleus}

The laterodorsal tegmental nucleus (figs. 13 and 14) appears in planes through the inferior colliculus but well behind the level of the trochlear nucleus. It consists of scattered neurons located at the edge of the central gray in relation with the medial border of the superior cerebellar peduncle. Its cells are characteristically deep staining, medium-sized, multipolar neurons, showing no definite nuclear arrangement, but intermingled with the general gray of the area. There is no demarcation between this nuclear mass and the cluster of similar, larger and smaller neurons which constitute the socalled marginal nucleus of the superior cerebellar peduncle. Gradually, as the sections are followed caudally, the neurons belonging to the laterodorsal tegmental nucleus increase both within the central gray and ventral to it, but otherwise maintain the same general relations. As the region of the isthmus is approached, at levels marking the decussation of the trochlear nerve, the dorsal tip of the laterodorsal tegmental nucleus swings dorsally and laterally into relation with the cells of the mesencephalic root of $\mathrm{V}$. This portion of the nucleus (fig. 14) shows some slight pigmentation and represents the nucleus of locus coeruleus. The medial part of the laterodorsal tegmental nucleus spreads along the dorsolateral border of the dorsal tegmental nucleus and gradually disappears, although neurons of similar type, lying medial to the dorsal tegmental nucleus for some little distance, may possible belong to the laterodorsal tegmental complex.

\section{Dorsal tegmental nucleus}

Rostrally, the dorsal tegmental nucleus (figs. 13 and 14) begins at the caudal end of the mesencephalon, lying medial to the laterodorsal tegmental nucleus, which forms its lateral border and caps it dorsolaterally. The dorsal tegmental nucleus is small-celled, relatively compact, and, slightly behind its rostral pole, acquires a rounded outline. It extends caudalward through the isthmus (fig. 14) to planes cutting the motor nucleus of $\mathrm{V}$ and then gradually fades out into the periventricular gray of the pons. It is a relatively discrete nucleus which maintains the same general appearance throughout its extent. Its cells are smaller and more closely placed than those of the laterodorsal tegmental nucleus.

\section{Nucleus of mesencephalic root of $V$}

Weinberg ('28) described this nucleus in considerable detail for the monkey, using part of the material available for the present paper. Those interested are referred to the work of this observer and figures 9 to 14 of the present paper. 


\section{MIDTEGMENTAL NUCLEAR GROUPS}

Nuclear groups associated with medial longitudinal fasciculus

The rostral end of the interstitial nucleus of the medial longitudinal fasciculus (fig. 3 ) invades the caudal end of the diencephalon, lying medial to zona incerta. Its rostral termination is rather abrupt. Slightly behind its frontal tip, it is a fairly large and quite well circumscribed nucleus (figs. 4 to 6 ). It consists of medium-sized to large, multipolar neurons of the general type of the larger cells of the reticular gray. It overlies and partly intermingles with the fascicles of the medial longitudinal fasciculus. At planes through the rostral end of the oculomotor complex, the interstitial nucleus of the medial longitudinal fasciculus lies dorsolateral to the Edinger-Westphal nucleus (fig. 4) and behind this level (figs. 5 and 6 ) has approximately the same relation to the chief oculomotor nuclear group. The nucleus of the medial longitudinal fasciculus gradually reduces in size through the rostral end of the nucleus of Darkschewitsch, but continues behind the caudal pole of this latter nucleus, disappearing in planes through the rostral end of the superior collicular commissure and the rostral part of the magnocellular portion of the red nucleus. It ends, as it began, somewhat abruptly.

The annular nucleus is not very completely developed in the macaque, although it does have representation at some levels. Thus in planes toward the caudal end of the oculomotor complex, there is a collection of cells representative of an annular nucleus along the ventral side and the ventromedial angle of the medial longitudinal fasciculus (figs. 8 and 9). Similar clusters of cells also persist into trochlear levels (fig. 10), where they lie dorsomedial and then dorsal to the fasciculus in planes through the trochlear nucleus (fig. 10). Caudal to this latter nucleus, cells belonging to the annular group lie along the fascicles of the medial longitudinal fasciculus and, in irregular tiny clusters, at its outer border (figs. 11 and 12).

\section{Red nucleus}

Compared with the red nucleus of subprimate forms, that of the macaque shows certain interesting differences, the most important of which are the great increase in size and the forward continuation of the parvocellular portion and the marked decrease in cell content of the magnocellular portion.

The caudal pole of the magnocellular part of the red nucleus (fig. 7 ) lies in planes through the midregions of the oculomotor complex and the caudal end of the medial geniculate nucleus. It extends forward for approximately $2.25 \mathrm{~mm}$, the last $.75 \mathrm{~mm}$. of its rostral extent 
(fig. 4) being indicated only by the presence of scattered cells. At no level is it characterized by any great number of neurons but there is a tendency to maintain the rounded outline (figs. 4 to 7 ) generally characteristic of this part of the nucleus in mammals, the spaces between the cells being occupied by fiber tracts. The constituent neurons are the typical large, multipolar cells characteristic of the larger elements of the tegmental gray.

In the caudal third of the red nucleus there is some tendency toward a separation into medial and lateral portions (fig. 6). This separation is brought about by fibers of passage which are a part of the tectal discharge paths.

The parvocellular portion of the red nucleus begins rostrally within the diencephalon, medial and slightly ventromedial to zona incerta. Its frontal pole is rather bluntly rounded and the nucleus soon takes on a round to oval outline (fig. 2). This outline is maintained, even with the increasing diameter of the nucleus, until the parvocellular portion intermingles with the magnocellular part (fig. 4) after which the whole red nucleus assumes a more or less rounded outline (figs. 5 to 7). As the two portions come together, the magnocellular portion lies on the lateral border of the parvocellular part and thereafter the latter reduces rapidly and soon completely disappears. Its total length is slightly over $3 \mathrm{~mm}$. The parvocellular portion of the red nucleus is much more cellular in content, although its medium-sized, less deeply stained neurons are less conspicuous than those of the magnocellular part. The Nissl material suggests that the parvocellular portion is made up of correlative cells, the magnocellular portion of efferent neurons. The cells of the parvocellular portion are much more closely arranged than those of the magnocellular part, being distinctly less intermingled with fiber tracts.

\section{Deep mesencephalic gray (nucleus mesencephalicus profundus)}

At the rostral end of the mesencephalon, not only is there a reduction in the magnocellular portion of the red nucleus but also a marked deerease in the large cells of the tegmentum as compared with the number of such neurons in the homologous region of many subprimates. Frequently only one or two of such cells are visible in a given cross section. As the level of the decussation of the superior cerebellar peduncle is approached, caudal to the red nucleus, the number of large efferent type neurons in the tegmentum increases and at the crossing (figs. 7 to 10 ), capping the ends of the commissural fibers. there is a considerable collection of such large cells, pars lateralis of nucleus mesencephalicus profundus. This suggests a primordial caudal red nucleus. Lateral and dorsolateral to these, lies a similar group 
(fig. 10) and others lie ventral to the crossing fibers (fig. 7). Behind the plane of this decussation, the large-celled more lateral elements follow along the fibers of the superior cerebellar peduncle (figs. 11 to 13) to become continuous with its marginal nucleus (fig. 14).

\section{Ventral tegmental area and nucleus of mammillary peduncle}

The ventral tegmental area of Tsai (figs. 2 to 4 ) lies at the rostral end of the midbrain. It is directly continuous with the lateral hypothalamic gray rostrally, and caudally extends to planes cutting the frontal pole of the interpeduncular nucleus. Throughout its extent, except for its most caudal tip, it lies lateral and dorsolateral to the mammillary body and medial to the medial border of substantia nigra but separated from this latter, for most of its extent, by the poorly developed nucleus of the basal optic root. The ventral tegmental area is ventral to the ventral tegmental decussation caudally. It consists of medium-sized, darkly staining, multipolar neurons in relationship with the mammillary peduncle. Papez ('23, '32) has termed a portion of this region the interstitial nucleus of the mammillary peduncle, the name being applied to cells lying in intimate relation with this fiber bundle. Aecording to Fox ('41; and probably, according to Papez) these cells are in synaptic relation with the fibers of the peduncle. In the monkey, then, the ventral tegmental area and the nucleus of the mammillary peduncle are greatly intermingled.

\section{Nuoleus medialis profundus}

Nucleus medialis profundus (fig. 14) is not a midbrain nucleus in the monkey. It lies ventral to the medial longitudinal fasciculus, at the lower end of the isthmus in planes through the nucleus of locus coeruleus and the caudal pole of the dorsal tegmental nucleus. It is a relatively small gray mass rounded in cross section and composed of medium-sized, deeply stained neurons.

\section{Marginal nucleus of superior cerebellar peduncle}

This nuclear mass (figs. 11 to 14 ) consists of clusters of mediumsized and small neurons which accompany the superior cerebellar peduncle as it passes rostroventromedialward toward its decussation. The neurons are oriented parallel to the curved surface of the bundle. Rostrally they lie in part among the faseicles of this fiber system. Except for this arrangement, and their tendency toward forming small cell groups, the cells of this nucleus do not differ markedly from 
those of the surrounding areas although they are somewhat smaller than the cells of nucleus laterodorsalis tegmenti and of that portion of pars lateralis of nucleus mesencephalicus profundus, with which they are intermingled.

\section{Cuneiform area}

The cuneiform area (fig. 13) in the monkey lies at inferior collicular levels, in the interval between the inferior colliculus and the periventricular gray. It has the usual appearance of intermingled cells and fiber bundles, the fibers being partly efferent fascicles from the tectum and partly collaterals of $t$ ' e lateral lemniscus. The constituent cells are spindle-shaped, multipol $\mathbf{r}$, deeply staining neurons scattered among the fiber bundles.

\section{Certain pretectal and subtectal components of tegmentum}

Pretectal nucleus. The pretectal nucleus (not illustrated) has been described by various workers on the macaque brain (Barris and Ingram, '34) and therefore does not require a detailed description here. Its rostral pole appears dorsal to the posterior commissure and the nuclear mass continues caudalward from this position, lying chiefly within the frontal end of the superior collicular eminence. It is somewhat irregularly elliptical in shape and consists of medium-sized neurons. The cell mass is fairly well circumscribed from the surrounding areas, except at its caudal pole, where it fuses with the deep gray of the optic tectum. Ventrolateral to it, but sharply separated from it by fiber bundles, is the medial geniculate nucleus.

Nuclear gray associated with lateral lemniscus. The caudal ventral nucleus of the lateral lemniscus (figs. 12 to 14) is represented by scattered clusters of cells along this fiber bundle from the superior olive to the isthmus region and the caudal end of the inferior colliculus. Caudoventral to the base of the inferior colliculus a special accumulation of cells of the lateral lemniscus appears, the so-called caudodorsal part of the dorsal nucleus of the lateral lemniscus or the parabigeminal body (figs. 13 and 14). At midplanes this nucleus shows an outer border of small cells and an inner mass of larger and smaller intermingled neurons in the course of the fiber fascicles. It is not clearly encapsulated throughout, being more or less continuous with other clusters of like character along the course of the lateral lemniscus. From inferior collicular levels (fig. 12) the lateral lemniscus is accompanied forward (figs. 11 to 9 ) by a somewhat circumseribed mass of medium-sized to small neurons which is directly continuous with the ventral caudal part of the medial geniculate and which constitutes a rostral ventral nucleus of this bundle. 


\section{MIDLINE NUCLEAR GROUPS}

\section{Linear nuclear gray}

The rostral end of the linear cell group (figs. 2 to 4) appears dorsal to the commissure of Forel, but almost immediately swings ventralward so that its ventral tip lies immediately behind the crossing fibers. In this position it is replaced dorsally by the rostral end of the Edinger-Westphal complex, nucleus medianus anterior. Its ventral portion (fig. 4) extends caudalward for a few sections caudal to the commissure of Forel. Behind this point there is no representation of the rostral part of the linear nucleus. Some sections farther caudalward, through the plane of the ventral tegmental decussation, scattered cells make their appearance, along the course of the decussating fibers. These cells resemble those belonging to the linear group but do not show any vertical arrangement, actually serving as an interstitial nucleus for the commissure. Whether or not they would be considered a part of the linear group is a purely academic question. If so, they represent the intermediate or central (Castaldi, '23) division of this group (figs. 6 and 7 ). Behind the ventral tegmental decussation, cells in linear arrangement are found in the midline extending from the dorsal nucleus of the raphe to the superior cerebellar decussation, and, caudal to the decussation, become continuous with the median raphé of the pons. These cells constitute the caudal portion of the linear nucleus (figs. 8 to 12). The three subdivisions of the linear nucleus just considered correspond in general with those described by Castaldi ('23) in the mesencephalon and isthmus regions of the guinea pig. On the whole, the cells of the linear group are small, relatively deeply staining, spindle-shaped elements arranged in rows, usually one cell thick, vertical to the longitudinal axis of the brain and near the midline. In general the arrangement in the linear group is similar to that in the raphe of the pons and the medulla.

\section{Interstitial nucleus of commissure of Forel}

The interstitial nucleus of the commissure of Forel appears at the caudal end of the diencephalon in planes through the mammillary body and just in front of the associated commissure. Its cells become intermingled with the commissural fibers, lying in rows, approximately one cell thick, between the bundles and forming a mass at either end of the decussation. Through midlevels of the commissure, the gray swings lateralward to become continuous ventrolaterally with substantia nigra (fig. 2) and dorsolaterally and laterally with the small-celled part of the red nucleus. As the caudal limit of the decus. 
sating fibers appears, the cells of the interstitial nucleus decrease rapidly and soon disappear. On the whole, this nucleus is much less well developed than in most mammals.

\section{Interpeduncular nucleus}

The rostral pole of the interpeduncular nucleus (fig. 4) lies at the front end of the midbrain, between the emerging oculomotor roots. Its caudal pole is in planes through the rostral end of the pons (fig. 8). Consequently, throughout most of its extent (figs. 4 to 8 ) it occupies the ventral midline portion of the midbrain. Rostrally, there is an indentation of the gray, which vaguely suggests a bilateral grouping (fig. 4). Farther caudally, at some levels, it is broken up into secondary groups by fiber fascicles (figs. 5 and 7 ). At its caudal pole it is a median, ovoid nuclear mass (fig. 8). Throughout its extent, it shows no secondary groupings other than those impressed upon it by fiber bundles. Its cells are small, rather evenly distributed, and undifferentially stained.

\section{BASAL MIDBRAIN GRAY}

\section{Substantia nigra}

Substantia nigra shows the usual divisions into pars compacta, pars reticulata and pars lateralis (figs. 2 to 9 ). The rostral end of pars compacta appears in a plane through the caudal end of the mammillary body, the zona incerta, and the midportion of nucleus subthalamicus. Rostrally it lies over the middle part of the cerebral peduncle, medial to nucleus subthalamicus and dorsolateral to the nucleus of the basal optic root, from which it is only slightly separated. Gradually, in planes caudal to the mammillary body, substantia nigra (fig. 2) increases relatively rapidly in size and becomes intermingled, ventromedially, with the nucleus of the basal optic root, after which this latter nucleus soon disappears. Then substantia nigra swings down on the medial side of the peduncle. The nucleus of the basal optic root and pars compacta of substantia nigra have cells which so closely resemble each other in the monkey that it is quite impossible to draw any sharp line between them in the region where they intermingle. In these rostral planes, substantia nigra also spreads laterally, replacing the medial pole of nucleus subthalamicus, but for some distance rostrocaudally it is confined to the medial half, and later to the medial two-thirds, of the cerebral peduncle (figs. 2 to 4). It continues to spread lateralward (figs. 5 to 7 ). As planes 
through the caudal half of the medial geniculate nucleus are reached, pars lateralis (fig. 7) makes its appearance as scattered cells overlying the dorsolateral tip of the peduncle, dorsolateral to pars compacta of substantia nigra but separated from it by pars reticulata. Thereafter pars compacta (fig. 8) reduces gradually in size, especially medially and laterally, and disappears in transverse planes through the beginning of the pons.

Pars reticulata (figs. 2 to 8 ) is actually the extension of cells of the type of pars compacta among the fibers of the cerebral peduncle. It is practically coexistent with pars compacta but varies in its degree of representation from level to level, depending upon the number of cells which penetrate among the fibers of the peduncle.

Pars lateralis (fig. 7) begins rostrally as scattered neurons overlying the dorsolateral tip of the cerebral peduncle and ventral to the medial geniculate nucleus. At this rostral end, it is represented by a few scattered neurons. As the medial geniculate nucleus begins to disappear from the field, pars lateralis (fig. 8) extends dorsally along fiber fascicles, presumably those interrelating substantia nigra with the optic tectum, and continues in planes almost immediately behind the medial geniculate nucleus (fig. 9) for a short distance.

The characteristic cells of pars compacta and pars reticulata are medium-sized to large multipolar neurons, obviously of an efferent type, since their Nissl granules are relatively coarse. Pars lateralis is composed of similar cells, tending however to be slightly smaller on the average; a part of this difference may be due to the orientation of the cells.

The pigmentation is much less rich in substantia nigra of the monkey than in that of man, but its distribution follows about the same pattern. Rostrally it is scanty, but is fairly well distributed through the nucleus, although there is less in the dorsomedial portion than lateralward and in the lateral tip. Caudally it increases on the lateral side, but is almost lacking medially. It is to be found in pars compacta, pars reticularis and pars lateralis.

\section{Nucleus of basal optic root}

The nucleus of the basal optic root has been recently described for the monkey by Gillilan ('41). Since the description was written by a member of this group and based upon the material used for this report, no further account is necessary. The nucleus is labeled in the figures (fig. 2). 


\section{PART II. MAN}

\section{THE PERIVENTRICULAR GROUPS}

\section{General areas of periventricular gray}

The human periventricular gray has the subdivisions characteristic of this region in other mammals. Rostrally, it is continuous with the gray surrounding the ventricle at the caudal end of the diencephalon. Caudally, its dorsal and lateral portions disappear as the isthmus region is approached and its ventral portion becomes continuous with the periventricular pontine gray, there being no definite line of demarcation between these latter areas.

The dorsal part of the periventricular gray constitutes the deep or periventricular layer of the optic tectum. It need not be redescribed here (see Huber and Crosby, '43).

The lateral portion of the periventricular gray (figs. 16 to 22) occupies the region between the tectum and the deep sulcus limitans in the aqueduct region which serves as a boundary between it and the ventral part of the periventricular gray. Rostrally this lateral portion begins, without sharp demarcation from the diencephalic periventricular gray, in the region ventral to the posterior commissure. It is fairly well developed through the rostral third of the midbrain but, with the further increase of superior collicular areas, it becomes greatly reduced. Then with the appearance of the inferior colliculus it increases in amount for a time but again decreases as the isthmus region is approached, being continuous to some extent with the caudal portion of the central nucleus of the inferior colliculus. It fades out slightly caudal to the decussatio veli. Throughout its extent it has only a single differentiated nuclear group, pars centralis subcommissuralis of the nucleus of the posterior commissure. The major differentiation of the periventricular gray occurs in its ventral portion.

The ventral part of the periventricular gray (figs. 17 to 23 ) is present throughout the midbrain, being coextensive rostrally with that of the diencephalic periventricular region and caudally with the corresponding gray of the pons. Thus the nuclei differentiated from its more caudal portion are partly mesencephalic and partly pontine in position. Specialized nuclear groups, to be considered immediately, appear in this ventral periventricular region but surrounding them and filling the interstices between them is the undifferentiated gray. 
Nuclear groups associated with the posterior commissure

The nucleus of the posterior commissure (fig. 16) shows in all essentials the same relations recognized for it in other mammalian forms. It surrounds all surfaces of the commissure so that it is represented rostrally and caudally by single masses of cells (precommissural and postcommissural portions respectively) and in intervening areas by a medial periventricular portion (pars centralis subcommissuralis) and a lateral tegmental part (pars magnocellularis). On the whole it is rather less clearly differentiated and somewhat smaller in man than in many mammalian forms, a condition to be expected with the relative decrease in size of the commissure itself.

Extending among the commissural fibers toward the midline, but not into a median position in the material studied, are strands of cells which constitute an intracommissural portion of the nucleus of the commissure. This merges laterally with the magnocellular portion of the nucleus.

\section{Nucleus of Darkschewitsch}

The nucleus of Darkschewitsch (figs. 16 and 17) consists of a rather deeply staining mass of cells in the ventral part of the periventricular gray at the level of the parvocellular portion of the red nucleus and in planes through the interstitial nucleus of the medial longitudinal fasciculus, which lies ventrolateral to it in the tegmental region. It extends forward into the caudal end of the diencephalon and caudalward to planes through nucleus medianus anterior. The cells of the nucleus of Darkschewitsch are less elongated but of approximately the same size as those constituting this latter nucleus, but somewhat smaller than those of the interstitial nucleus of the medial longitudinal fasciculus.

\section{Eye-muscle nuclei}

Oculomotor complex. The oculomotor complex of man includes nucleus medianus anterior of Panegrossi ('04), or the rostral portion of the Edinger-Westphal nucleus, the main or caudal part of the Edinger-Westphal nucleus, the dorsolateral and ventromedial oculomotor nuclei, the paramedian oculomotor nucleus of Le Gros Clark ('26) or central nucleus of Perlia (1889), and the caudal central nucleus of Tsuchida ('06).

The nucleus medianus anterior (figs. 17 and 18), or rostral EdingerWestphal nucleus (see Le Gros Clark, '26), appears in planes through the parvocellular portion of the red nucleus, the caudal end of the nucleus of Darkschewitsch and the interstitial nucleus of the medial longitudinal fasciculus. It differentiates near the midline in the ventral 
part of the periventricular gray and keeps this same position throughout, but overrides the main oculomotor nucleus as this latter appears in the field, lying dorsal and dorsomedial to it. It is paired and consists of medium-sized, multipolar neurons of a general preganglionic character, resembling closely those of the main or caudal part of the Edinger-Westphal nucleus, from which it is separable on the basis of a discontinuity of gray rather than on differences in cell type. Zweig ('21) considered that it was a center associated with pupillary action. Although this is an entirely feasible suggestion, conclusive evidence that it contributes fibers to the human ciliary ganglion or that its stimulation produces a decrease in size of the pupil is not as yet fortheoming. The Edinger-Westphal nucleus proper (fig. 18), or the caudal Edinger-Westphal nucleus (Le Gros Clark, '26), begins in front of the rostral pole of the oculomotor complex but caudal to the front end of nucleus medianus anterior, to which it is dorsal. It extends caudalward, dorsomedial to the upper part of the chief oculomotor gray, to planes just in front of the magnocellular portion of the red nucleus. It is more discrete and better represented in cellular content but has a somewhat shorter rostrocaudal extent than does the rostral part of the complex, nucleus medianus anterior. Not only is this caudal portion paired, but it shows secondary bilateral subdivision into lateral and medial portions. Zweig ('21) regarded the Edinger-Westphal nucleus as concerned with accommodation although the validity of the evidence has been questioned from time to time. The recent paper by Mohney, Morgan, Olmsted and Wagman ('42), in which stimulation of the superior cervical ganglion resulted in a flattening of the lens in the cat, raises again the old question of accommodation. Although this nuclear gray has been recognized and described in a wide range of mammals, and a very considerable number of observers have regarded it as preganglionic in character, many workers, for example Latumeten (quoted from Le Gros Clark, '26), have failed to trace the neuraxes of its cells into the oculomotor roots in mammals. However such a connection appears to have been established for avian forms by Mesdag ('09) and Zweig ('21). The present observers are inclined to regard the caudal Edinger-Westphal nucleus, from the evidence at hand, as a preganglionic center associated with the oculomotor nerve, which is the customary interpretation. At present, however, they have no satisfactory evidence to support this contention, but hope to present soon some experimental data in connection with the study of the fiber paths of the midbrain tegmentum.

The chief oculomotor complex (figs. 18 and 19) appears in planes through the parvocellular portion of the red nucleus and the inter- 
stitial nucleus of the medial longitudinal fasciculus, as a single cell column which lies ventral and ventrolateral to the caudal portion of the Edinger-Westphal nucleus. Out of this common column of typical multipolar cells a dorsal portion, the representative of the dorsolateral oculomotor nucleus, can be indistinctly separated from a ventromedial oculomotor group. Between the two nuclei occasional scattered cells of a similar type are found, ventral to the caudal portion of the Edinger-Westphal nucleus. Behind this latter nucleus, the number of such cells slightly increases and a cluster of neurons of similar type (fig. 19) appears between the two dorsolateral nuclei. These are neither numerous nor conspicuous and fade out with the disappearance of the rest of the oculomotor complex, but they are the only representative of the paramedian group of Le Gros Clark ('26), or the central nucleus of Perlia, which it has been possible to identify. The major part of the oculomotor complex disappears in front of trochlear levels, but the ventromedial nucleus is practically continuous with the trochlear nucleus. A very slight cell continuity of the overlapping dorsolateral oculomotor nucleus with the trochlear complex can be demonstrated. A poorly differentiated posterior central nucleus overlaps the rostral pole of the trochlear complex for a very short distance, its position then being taken by the rostral end of the dorsal nucleus of the raphé.

The only possible representative of a nucleus centralis anterior in the material available for study is to be found in the scattered cells intervening between the oculomotor groups of the two sides, rostral and ventral to the central nucleus of Perlia.

Trochlear gray. The trochlear nucleus (fig. 20) is continuous with the ventromedial and, less distinctly, with the dorsolateral oculomotor nuclei rostrally. It extends into planes through the caudal end of the inferior colliculus and the rostral pole of the laterodorsal tegmental nucleus. Throughout it indents the dorsal surface of the medial longitudinal fasciculus. Its neurons are approximately the same size as those constituting the chief nuclei of the oculomotor, and otherwise resemble them. The root fibers have the usual course, passing dorsocaudalward around the periventricular gray to emerge, after decussation, immediately behind the inferior colliculus through the anterior medullary velum.

\section{Dorsal nucleus of raphé}

This nucleus begins rostrally in planes through the trochlear complex, immediately caudal to the poorly differentiated posterior central nucleus and not sharply separable from it. It extends caudally into the pons region, where it is continuous with the nucleus of the pontine 
raphé. Rostrally and caudally, for a very considerable extent (figs. 20 to 23), it consists of paired central masses which tend to fuse in the midline but, in intervening areas (fig. 20), it shows much greater differentiation. In such midregions it consists of a central portion and lateral wings. The central portion is secondarily divisible into dorsal, intermediate, and ventral parts (fig. 20). The intermediate portion is that subdivision of the dorsal nucleus of the raphé which is found throughout the extent of the nuclear mass. The dorsal part (fig. 20) is a specialized rounded mass of cells occurring throughout most of inferior collicular levels but disappearing rostrally and caudally. The ventral portion (fig. 20) appears behind the rostral end of the nucleus, lying between the two medial longitudinal fasciculi within the central gray and becomes continuous caudally with the pontine gray of the raphé. The lateral wings (which have been termed, in part at least, the supratrochlear nuclei by several authors) are found within the periventricular gray above the trochlear nucleus. They (fig. 20) begin slightly behind the rostral tip of the central part of the dorsal nucleus and disappear, before isthmus levels are reached, in a plane approximately through the rostral tip of the laterodorsal tegmental nucleus. Throughout trochlear levels they are conspicuous elements of the central gray.

The dorsal nucleus of the raphé as a whole is differentiable from the remainder of the central gray by the closer arrangement and deeper staining of its constituent cells, which are medium-sized, multipolar to spindle-shaped neurons with deeply staining Nissl granules.

\section{Laterodorsal tegmental nucleus}

The laterodorsal tegmental nucleus (figs. 21 and 22) appears rostrally in planes through the caudal tips of the lateral wings of the dorsal nucleus of the raphé, behind the caudal pole of the trochlear nucleus, but in planes in which the inferior colliculus is still found in the dorsal part of the field. From this point the laterodorsal tegmental nucleus extends backward through the isthmus region into rostral levels of the pons, disappearing in planes through the sensory nucleus of the trigeminal nerve. In most rostral levels (fig. 21) it occupies the lateral part of the ventral portion of the periventricular gray and consists of multipolar neurons, partly pigmented and partly unpigmented, which spread out into the underlying tegmentum. Gradually the nucleus increases dorsomedially and, with the appearance of the dorsal tegmental nucleus, lies dorsolateral and lateral to this latter cell mass (fig. 22). At isthmus levels there is a tendency for the proportionate amount of pigmentation to increase and the more lateral part of the nucleus becomes intermingled with the cells of 
the mesencephalic nucleus of $\mathrm{V}$ (fig. 23). The two types of cells are easily distinguishable, however, since those of the laterodorsal tegmental nucleus are multipolar and pigmented and those of the mesencephalic root of $\mathrm{V}$ are unpigmented and, for the greater part, unipolar. The more medial cells of the laterodorsal tegmental nucleus in this region show somewhat less pigmentation. As the caudal pole of the nucleus is reached, the more medial cells disappear and only the lateral cells remain. This lateral part of nucleus laterodorsalis teg. menti, particularly its caudal lateral portion, which is so closely related to the mesencephalic root of $\mathrm{V}$, constitutes the so-called nucleus of locus coeruleus (fig. 23). Whether or not one should include with such pigmented cells their unpigmented accompaniments under the term, nucleus of locus coeruleus (as Castaldi has done in his homologies), is a purely academic question. The amount of pigmentation in the laterodorsal tegmental nucleus of man is greater than that of any other form studied in this series.

\section{Dorsal tegmental nucleus}

The dorsal tegmental nucleus (fig. 22) makes its appearance in the isthmus region, between the central portion of the dorsal nucleus of the raphé medially and the Iaterodorsal tegmental nucleus Iaterally. It is present in planes which show the decussatio veli above the aqueduct. The dorsal tegmental nueleus is a differentiation of the ventral part of the central gray in the region overlying the medial longitudinal fasciculus. Unlike the masses of gray medial and lateral to it, it is composed of small, less deeply stained, and somewhat more closely arranged neurons. Traced backward from its rostral pole, the nucleus increases in size and takes on a circular outline in cross sections. It is found caudalward as far as upper pontine levels, disappearing, however, in front of the caudal pole of nucleus laterodorsalis tegmenti.

\section{$N$ ucleus of mesencephalic root of $V$}

The human nucleus of the mesencephalic root of $V$ (figs. 17 to 23) was studied in this laboratory by Weinberg ('28). His description was based on the material available for this report. Those interested are referred to his account.

\section{MIDTEGMENTAL NUCIEAR GROUPS}

The main nuclear constituents of the midtegmental groups are the nuclei associated with the medial longitudinal fasciculus, the red nucleus, the more scattered, deep tegmental gray, nucleus mesen- 
cephalicus profundus, nucleus medialis profundus and certain pretectal and subtectal gray. In addition to the more differentiated masses found in the midtegmental regions, there is a very considerable amount of relatively unorganized gray composed of mediumsized, less deeply stained neurons, intercalated among the fiber masses of the region but showing no regular nuclear pattern.

\section{Nuclear groups associated with medial longitudinal fasciculus}

Two midbrain nuclear groups are related to the medial longitudinal fasciculus, although other cell masses in this and other regions contribute components to this fiber bundle. These two nuclei are the interstitial nucleus of the medial longitudinal fasciculus and the annular nucleus of Castaldi ('24).

Like the nucleus of Darkschewitsch, the interstitial nucleus of the medial longitudinal fasciculus (figs. 16 and 17) makes its appearance in man in the diencephalic-mesencephalic transition area (fig. 16). It does not belong to the periventricular gray but to the tegmental area immediately adjacent. It extends caudalward behind the nucleus of Darkschewitsch into planes through the caudal end of the EdingerWestphal nucleus and the rostral pole of the chief oculomotor complex. Throughout its extent it is ventrolateral to the nucleus of Darkschewitsch. It overrides the medial longitudinal fasciculus and certain of its cells extend among the fascicles. It is probably to be regarded as a differentiation of tegmental gray associated with fibers of this fasciculus. The cells are multipolar and obviously efferent in character, being slightly larger than those of the surrounding tegmental gray and of the nucleus of Darkschewitsch.

The annular nucleus (figs. 18 and 20 ) is exceedingly poorly represented in man. For the most part it consists merely of occasional cells around the periphery or intermingled with the fascicles of the medial longitudinal fasciculus. Rarely, as in the level illustrated (fig. 18) through the parvocellular portion of the red nucleus, the chief oculomotor complex and the caudal part of the Edinger-Westphal nucleus, a cluster of such neurons suggests a very poorly developed annular group. Similar small masses of cells are found at planes through the trochlear nucleus (fig. 20) but at no place is there a complete ring surrounding the medial longitudinal fasciculus such as Castaldi ('24) described in the guinea pig.

\section{Red nucleus}

The red nucleus in man, as in other mammals, consists of two major subdivisions, a parvocellular portion (figs. 16 to 18) and a magnocellular portion (fig. 19). The parvocellular portion is larger 
and has a relatively greater extent in man than in the other primates studied, and is larger in primates than in subprimate forms. In the human midbrain it is a very conspicuous nuclear element, occupying a considerable portion of the tegmentum in levels through the oculomotor nuclei and extending forward into the caudal end of the diencephalon. Its cells are small to medium-sized, are more closely arranged than those of the magnocellular part and are interspersed with fibers bundles. The mass is relatively distinctly separated from the surrounding areas by encapsulating fibers. Rostrally, it begins as somewhat scattered neurons but soon takes on, in cross sections, a rounded outline and, through its greatest extent, has a circular form (figs. 16 to 18 ) except as this is broken into by the passage of the habenulo-peduncular tract (fig. 16). As the caudal end of the oculomotor complex is reached, the parvocellular portion begins to disappear medially and its contour becomes crescentic, surrounding laterally, the very poorly developed magnocellular part of the complex (fig. 19). This crescent-shaped mass soon reduces to a patch of cells on the ventrolateral border of the nucleus and then disappears in front of the trochlear nucleus and rostral to the decussation of the superior cerebellar peduncle.

The magnocellular portion of the red nucleus (fig. 19) is present only in the caudal third of the complex, appearing dorsomedial to the parvocellular part and gradually encroaching upon the latter to form the whole nuclear mass immediately rostral to the decussation of the superior cerebellar peduncle. This magnocellular portion has large, multipolar neurons of an efferent type comparable to those found in other forms, but these are relatively very few in number. At some levels only two or three neurons of the characteristic type are found in the field; oceasionally there is a section in which not more than one or two neurons are distinguishable and rarely there are clusters of eight or ten in the area in a single plane. The greater part of the so-called magnocellular portion of the nucleus is filled up by fascicles, many of which are fibers of passage. Thus the magnocellular portion of the human red nucleus is reduced to a minimum, its recognition depending upon comparison with other forms rather than upon richness of cellular content. On the contrary, the parvocellular portion of the nucleus is better developed in man than in any other mammal available for study. There is pigmentation in the red nucleus, particularly in some of the medium-sized cells of the magnocellular portion. In the material available the large cells do not exhibit pigmentation but it must be borne in mind that the available sections are from post mortem material, received some time after death had occurred. 


\section{Deep mesencephalic gray (nucleus mesencephalicus profundus)}

The deep tegmental gray (nucleus mesencephalicus profundus) consists of the more scattered, larger elements and clusters of such cells found throughout the tegmentum of the midbrain. Some of these neurons appear to contain pigment, although this is lacking in the material studied in the largest cells. Rostrally this gray finds little representation except for a small dorsomedial patch of cells along the inner, upper border of the red nucleus close to its capsule, which constitutes a pars dorsalis of nucleus mesencephalicus profundus (figs. 18 and 19) and for somewhat scattered elements between the red nucleus and substantia nigra, which suggest a pars ventralis of the complex (figs. 18 and 19). In addition there are widely dispersed neurons of this type which do not show sufficient arrangement to justify the term nucleus. In planes which pass through the posterior capsule of the nueleus, pars ventralis of nucleus mesencephalicus profundus has increased in amount, forming a ring of cells which embraces the ventral, ventromedial and ventrolateral regions of the capsule (fig. 20) and passes over without sharp demarcation into substantia nigra.

Likewise, a relatively discrete cell mass appears in the lateral part of the field, dorsolateral to the capsule of the red nucleus, which forms a pars lateralis of nucleus mesencephalicus profundus (figs. 20 and 21). Pars ventralis continues through the level of the superior cerebellar decussation (fig. 21) and ultimately passes over into the tegmental gray of the pons. Pars lateralis extends caudalward (fig. 21 ) into the region of the superior cerebellar decussation and there becomes intimately associated with the marginal nucleus of the superior cerebellar peduncle (fig. 21), the two together forming a relatively large mass of nuclear gray, which, however, disappears caudal to the decussation. A poorly differentiated cluster of tegmental gray dorsal to the decussation and dorsomedial to the nucleus of the superior cerebellar peduncle and pars lateralis of nucleus mesencephalicus profundus constitutes a more caudal pars dorsalis of this latter nucleus (fig. 21). This pars dorsalis continues behind the level of the decussation into a plane which cuts the dorsal tegmental nucleus (figs. 22) and then gradually fades out into the tegmental gray of the pons (figs. 23). Behind the decussation the large-celled tegmental elements tend to accumulate into a mass of cells in the midtegmental field, which passes over into the pontine tegmental gray and which may be termed an intermediate portion of nucleus mesencephalicus profundus (fig. 22). It is possible to demonstrate some pigment in these cells but the cells showing pigment tend also to have post mortem characteristics. 
Ventral tegmental area and nucleus of mammillary peduncle

$\Lambda$ rea ventralis tegmenti of Tsai ('25) is the name applied to the relatively undifferentiated gray (figs. 16 to 20 ) medial to the nucleus of the basal optic root and substantia nigra. Rostrally it occupies the region above the interpeduncular fossa (figs. 16 to 19), but with the appearance of the interpeduncular nucleus it lies between that nucleus and the gray masses associated with the peduncle (fig. 20). Dorsally it grades over into the bed nuclei associated with the commissure of Forel (fig. 16) and the ventral tegmental decussation. A special group of cells within this gray mass surrounds the fibers of the mammillary peduncle and to this group Papez ('23 and '32 for armadillo) and others (for example, Fox, '41) have applied the term interstitial nucleus of the mammillary peduncle. Area ventralis tegmenti consists of medium-sized and small cells, showing no special arrangement except that already mentioned. Here, as in other mammals, it has the appearance of being composed of relatively undifferentiated gray.

\section{Nucleus medialis profundus - nucleus ventralis tegmenti}

The only cluster of cells in man, which appears to correspond at all satisfactorily with nucleus medialis profundus or the ventral tegmental nucleus for subprimate forms, is a small patch of neurons beneath, and partly embedded in, the medial longitudinal fasciculus behind the mesencephalon in lower isthmus regions. This patch of cells persists for only a few sections and has the appearance of being merely a condensation of tegmental gray. At present nothing is known of its connections or significance in man.

\section{Marginal nucleus of superior cerebellar peduncle}

As the superior cerebellar peduncle swings ventrorostralward toward its decussation, it is accompanied, on its lateral side, by a mass of deeply staining, medium-sized neurons which constitute a marginal nucleus of the peduncle. This nucleus meets and fuses with pars lateralis of nucleus mesencephalicus profundus (fig. 21), the two together forming a single nuclear mass, which disappears immediately behind the level of the decussation.

\section{Cuneiform area}

The cuneiform area in man (fig. 21) has precisely the same relations as described for it in the monkey, being an area of intercalated cells and fiber fascicles between the inferior colliculus and the periventricular gray. 


\section{Certain pretectal and subtectal components of tegmentum}

Pretectal nucleus. The human pretectal nucleus appears rostrally as a few scattered cells overlying the upper border of the posterior commissure. With the exception of this rostral tip, the nucleus lies within the superior collicular eminence, although its front end is rostral to well established tectal layers and it is not included in the tectal gray. Throughout its midplanes, it appears in transverse sections as an obliquely oval mass of medium-sized and smaller neurons, lateral to the more rostral portions of the tectal gray and medial to the large-celled nucleus of the optic tract and the pulvinar. It has a relatively short rostrocaudal extent in the material studied. Its caudal pole lies in intimate relation with stratum griseum mediale of the optic tectum and ultimately fades out into this layer. Its relations are essentially the same as those described for the monkey and for various subprimates, except that it lies more completely within the collicular eminence than does its homologue in the latter forms.

\section{Nuclear gray associated with lateral lemniscus}

Along the course of the lateral lemniscus, from its accumulation near the superior olivary nucleus of the pons to its termination in the medial geniculate nucleus, there are clusters of neurons which collectively constitute nuclei of the lateral lemniscus. Such nuclei are present in mammals and many submammals, but the particular pattern varies from form to form and it seems probable in some instances from one individual to another. Usually about four groups can be distinguished, which are secondarily connected by more or less scattered masses of cells. The first of these is a caudal ventral group, lateral and dorsolateral to the superior olivary nucleus at pontine levels and extending forward into the isthmus region (fig. 23). The second group is an isthmus group, at about the region of the decussation of the commissura veli behind the inferior colliculus. This mass lies both medial and lateral to the lemniscal fibers and frequently its lateral part shows a differentiation into a superficial band and a deeper portion. This constitutes a caudodorsal part of the dorsal nucleus of the lateral lemniscus (figs. 22 and 23). From it, seattered cells accompany the fibers passing to the inferior colliculus (fig. 21). Other more ventrally situated cell masses lie at mesencephalic levels, caudal to the medial geniculate nucleus and lateral and dorsolateral to the cerebral peduncle. They constitute a rostral ventral nucleus (fig. 20), which may show a marked accumulation of cells immediately medial to the caudal part of the medial geniculate nucleus, where the lateral lemniscus fibers enter the nucleus, such cells becoming continuous with the medial geniculate gray. 
It should be emphasized that these groups are simply exaggerations of an almost continuous interstitial nucleus, which is partly embedded among the fibers of the lateral lemniscus and lies in part along its inner and outer borders. It is probable that the isthmus group corresponds to the nucleus isthmi of lower forms.

\section{MIDLINE NUCLEAR GROUPS}

\section{Linear nuclear gray}

The linear nucleus (figs. 16 to 22 ) is present throughout the extent of the mesencephalon, although not equally well differentiated at the various levels. The rostral portion of the nucleus (fig. 16) is continuous frontally with the periventricular diencephalic gray, overriding the commissure of Forel and continuing slightly in front of it. The intermediate or central part (figs. 17 to 19) lies behind the commissure of Forel and extends to the region of the superior cerebellar decussation; the caudal portion (figs. 21 and 20) overlies that decussation and stretches backward to become continuous with the median raphé of the pons. Rostrally, and in its midportions, the linear nucleus is relatively poorly developed, consisting of sparsely arranged, spindleshaped neurons interspersed among the fibers of the periventricular system. It is replaced by commissural fascicles, so that its dorsoventral extent depends somewhat upon the bundles crossing the midline.

The number of cells in the nucleus increases toward the caudal end of the midbrain, a considerable cluster of neurons overlying the superior cerebellar decussation and passing backward to continue as the median pontine raphé. At no place is the linear group a conspicuous element of the nuclear pattern in man.

\section{Interstitial nucleus of commissure of Forel}

The crossing fibers of the commissure of Forel are embedded in the nuclear gray (fig. 16) which surrounds its rostral and caudal borders and overlaps it dorsally and ventrally. Very few such cells are intercalated among the fascicles in the midline but, as the bundles spread out toward the nucleus of the basal optic root, substantia nigra and the red nucleus, the interstitial cells increase in amount and form bands of gray which become continuous with the nuclei in question, as the fibers relate themselves to these cell groups.

\section{Interpeduncular nucleus}

The human interpeduncular nucleus (fig. 20) has a relatively short extent compared to its length in many other mammals studied, 
the rostral end of the nucleus being the portion not developed. In man it extends from planes just in front of the superior cerebellar decussation to pontine gray. It occupies the usual position at the base of the midbrain, in the midline above the interpeduncular fossa. It consists of a rounded gray mass, broken by fiber bundles. Its neurons are small, not very deeply stained, and show no outstanding differential characteristics. It is quite well separated from the surrounding gray by fiber fascicles, there actually being an encapsulating band of fibers over its dorsal and lateral surfaces.

\section{BASAL MIDBRAIN GRAY}

\section{Substantia nigra}

Substantia nigra extends from the caudal end of the diencephalon to the pons, its rostral tip lying in a plane slightly behind that of the most frontal extension of the parvocellular portion of the red nucleus. It replaces nucleus subthalamicus, which is very large in man.

Pars reticulata of substantia nigra (figs. 16 to 20) has the greatest rostrocaudal extent of the three usual divisions, being present from the anterior end to the caudal pole of the complex. It is characterized, as in other mammals, by the distribution of its elements among the fibers of the peduncle. The typical cells are multipolar neurons, many of which contain pigment.

Pars compacta (figs. 17 to 20 ) begins slightly behind the rostral pole of pars reticulata and continues caudally throughout the remainder of substantia nigra. It is very large proportionately, throughout most of its extent. Lateralward it is represented by a relatively closely packed mass of cells similar to those of pars reticulata and, in part, pigmented. Ventromedially, this cell mass has a tendency to split into deep and superficial portions. The deep portion extends somewhat farther medialward, where it terminates as a band of slightly smaller pigmented cells.

Pars lateralis of substantia nigra (figs. 17 to 19) appears at the lateral tip of the nuclear mass, ventral to the medial geniculate nucleus, and extends dorsalward behind that latter nucleus along the course of nigro-tectal connections. On the whole, it is relatively poorly developed in man but does show the pigmentation typical of much of the rest of the nuclear mass.

There is pigment throughout the extent of the human substantia nigra, but the amount of such pigment varies at different planes and in different portions of the same plane. Rostrally, the lateral part of the complex is heavily pigmented, the greater proportion of the cells showing this phenomenon, but medialward, the proportionate amount of pigment gradually diminishes and, in the most 
medial region of the nucleus, external to the small-celled pigmented tip, only part of the neurons contain granules of this type. As the nucleus is followed caudalward there is a gradual decrease in the number of cells which show such inclusions, so that at the caudal pole there is practically no pigmentation in the medial half of the nucleus and many of the neurons in the lateral half are unpigmented. It seems quite probable that the amount of pigment, and possibly the distribution, may vary not only with the age of the individual but in accordance with other factors. It is generally recognized that the substantia nigra of young children shows only slight pigmentation under normal conditions.

\section{Nucleus of basal optic root}

The nucleus of the basal optic root (fig. 17), as well as the root itself, has very poor representation in man. It consists of a few scattered cells medial to substantia nigra and not sharply separable from it. Internal to it is area ventralis tegmenti of Tsai. Nowhere is this nucleus clearly delimitable, although it is intermediate in cell type between area ventralis tegmenti and substantia nigra. It has been described by Gillilan ('41) and further reference to it need not be made here.

\section{SUMMARY}

The various nuclear groups considered in the foregoing account of the primate midbrain and isthmus are compared with their homologues in subprimate forms in the general summary which was prepared by the writers and which immediately follows this paper. Consequently no separate summary for the nuclear groups of the primate midbrain and isthmus is given here.

PLATES 1 TO 14

EXPLANATION OF FIGURES

1 Photograph of a midsagittal view of the brain of the macaque to scrve for orientation of the plane of section of figures 2 to 14 . $\times 4$.

2 to 14 Photomicrographs of transverse sections of the midbrain and isthmus regions of the macaque. The plane of section of these preparations is indicated in figure 1 . Toluidin blue preparations. $\times 10$.

15 Photograph of a midsagittal view of a human brain; the lines indicate the outer limits of the sections illustrated and the plane of sectioning.

16 to 23 Photomicrographs of transverse sections in the planes indicated in figure 15. Toluidin blue preparations. $\times 8$. 
PLATE 1

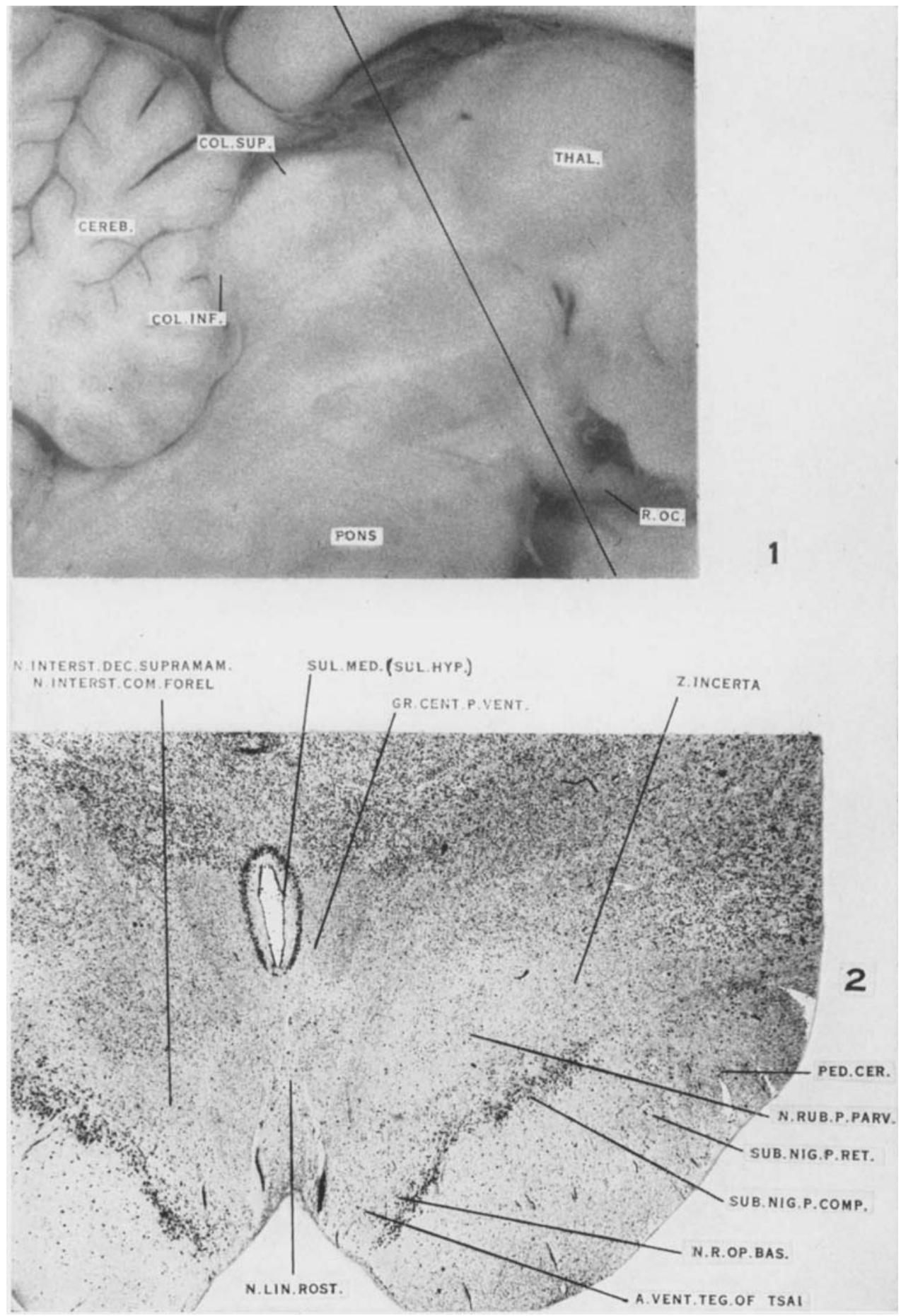


PLATE 2

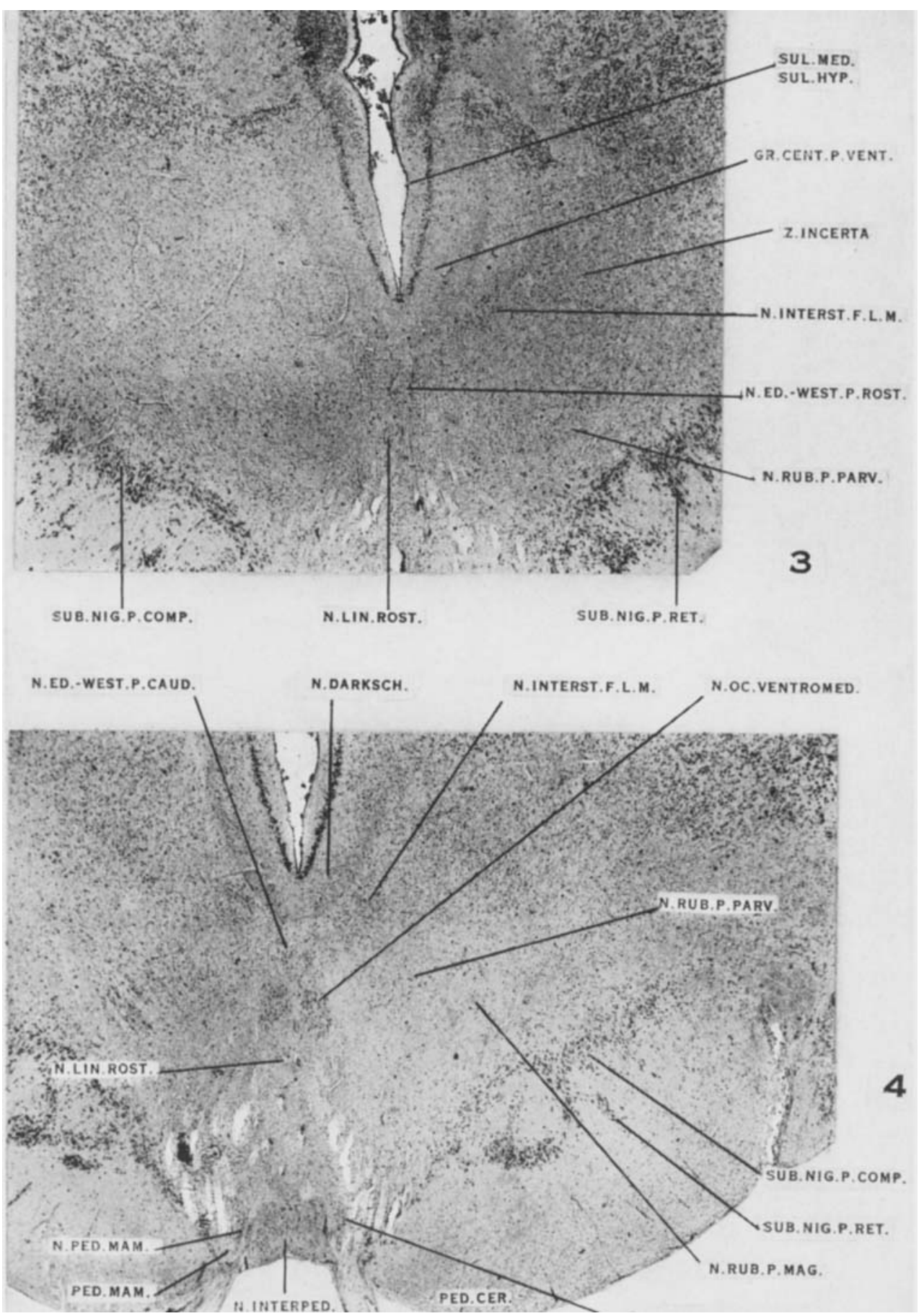


PLATE 3

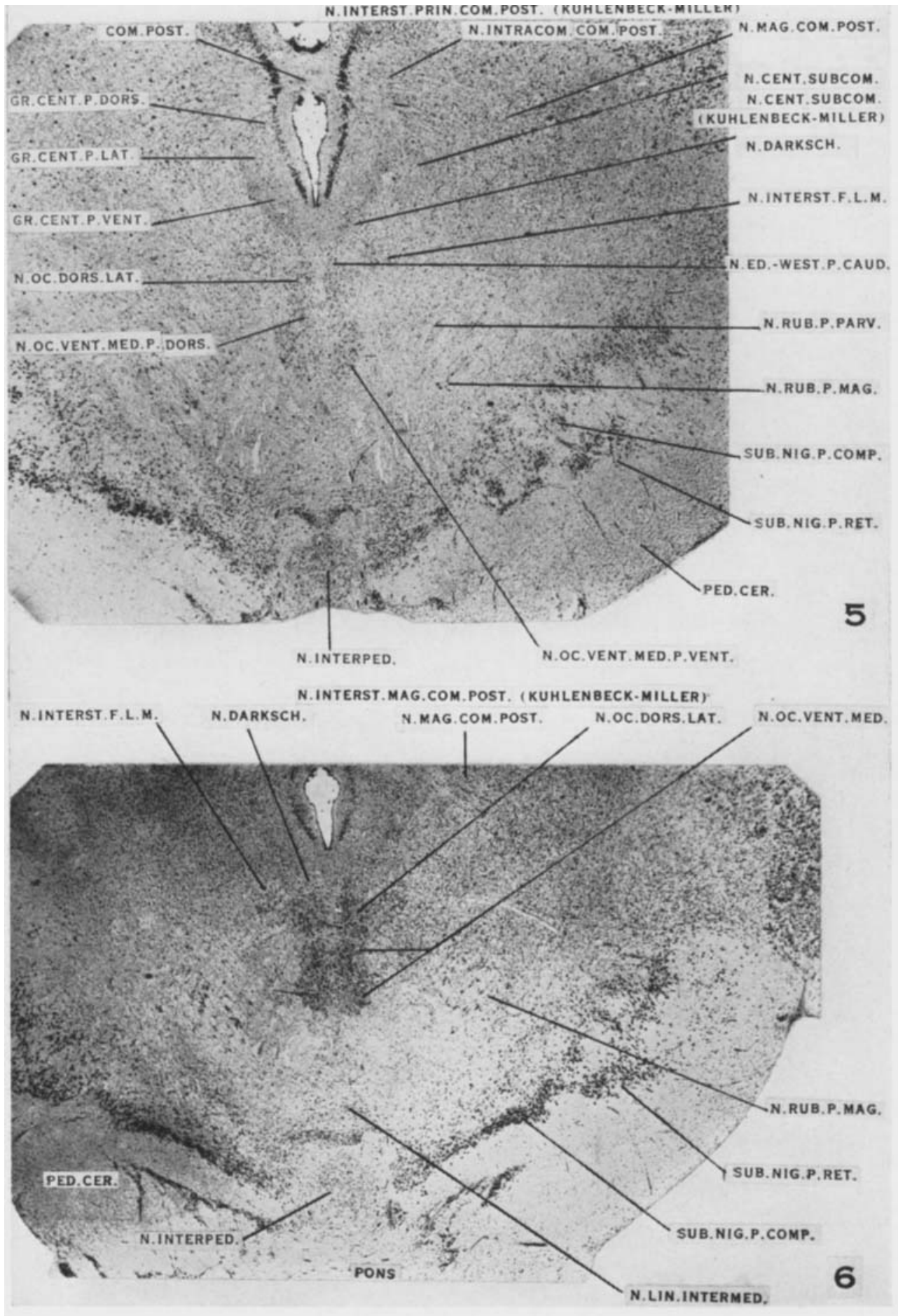




\section{PLA'TE 4}

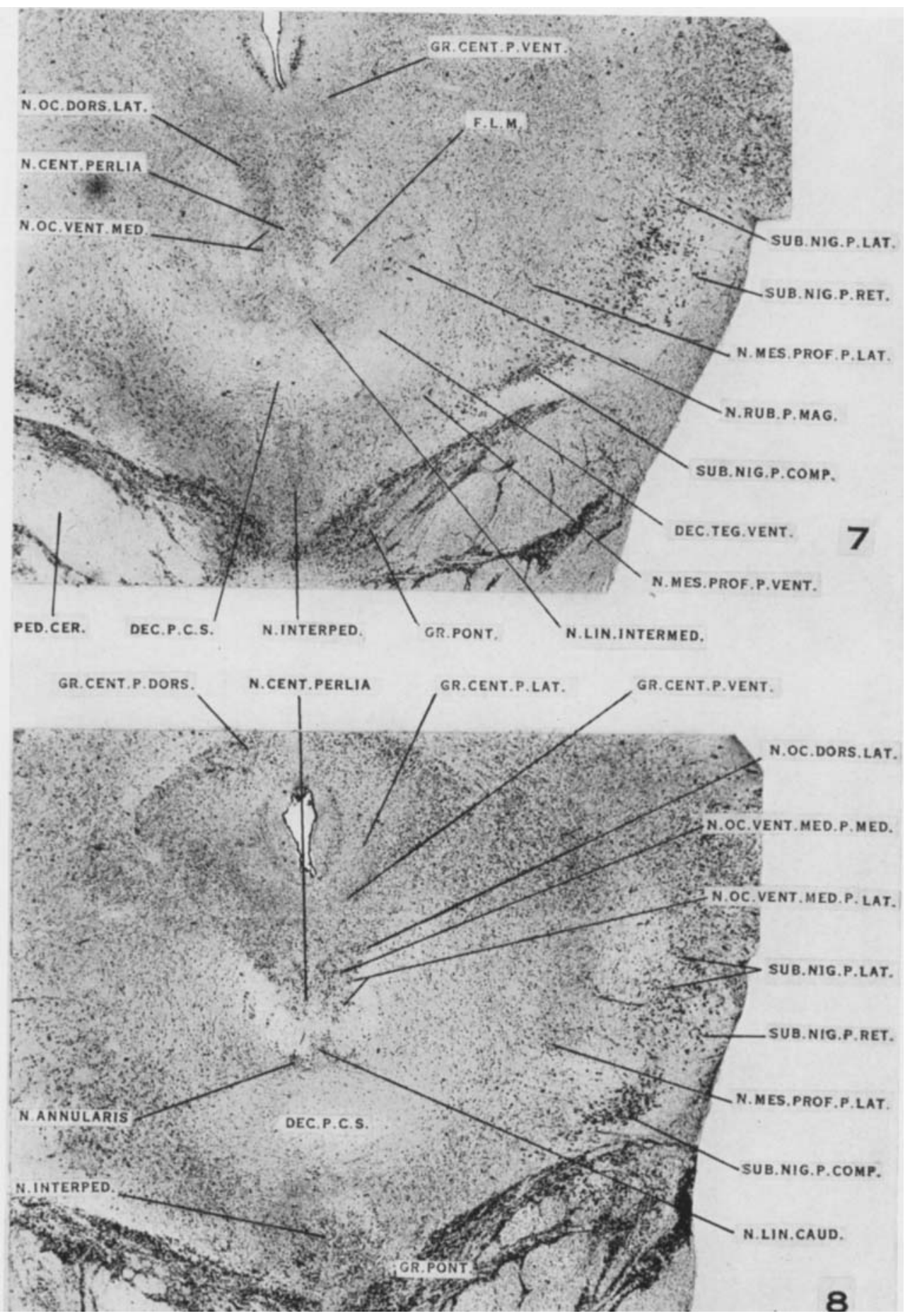


PLATE 5

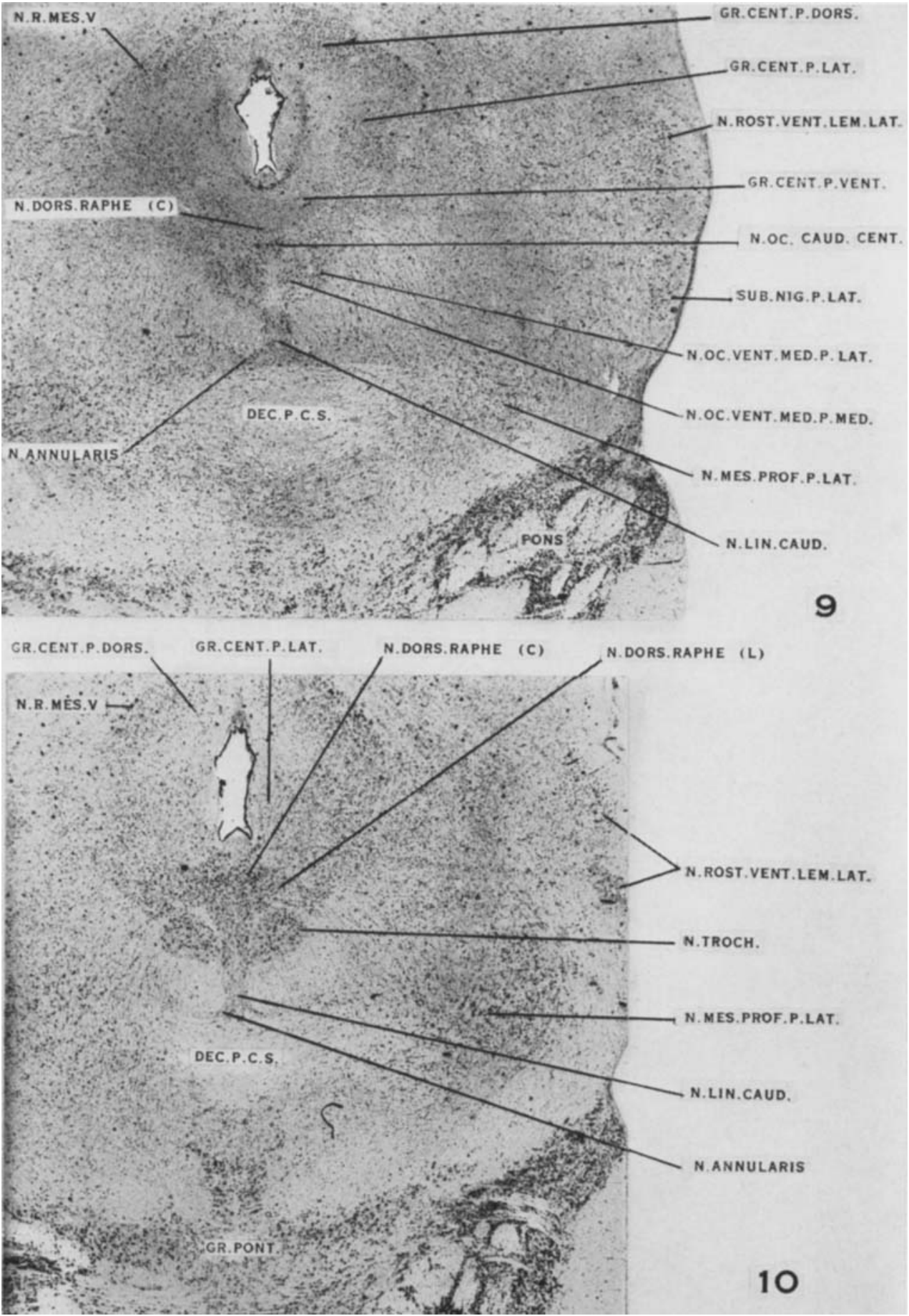


PLATE 6

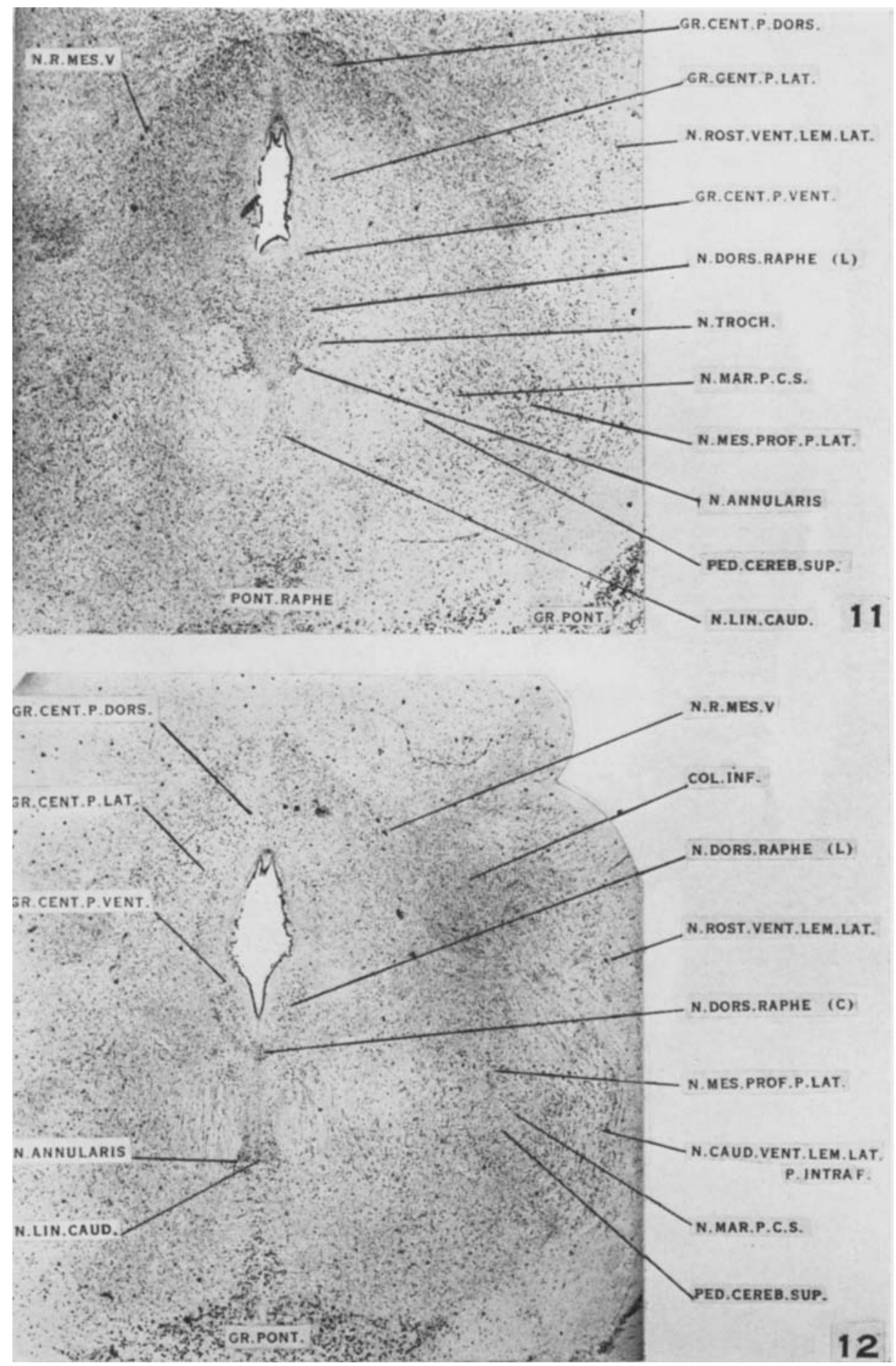


PLATE 7

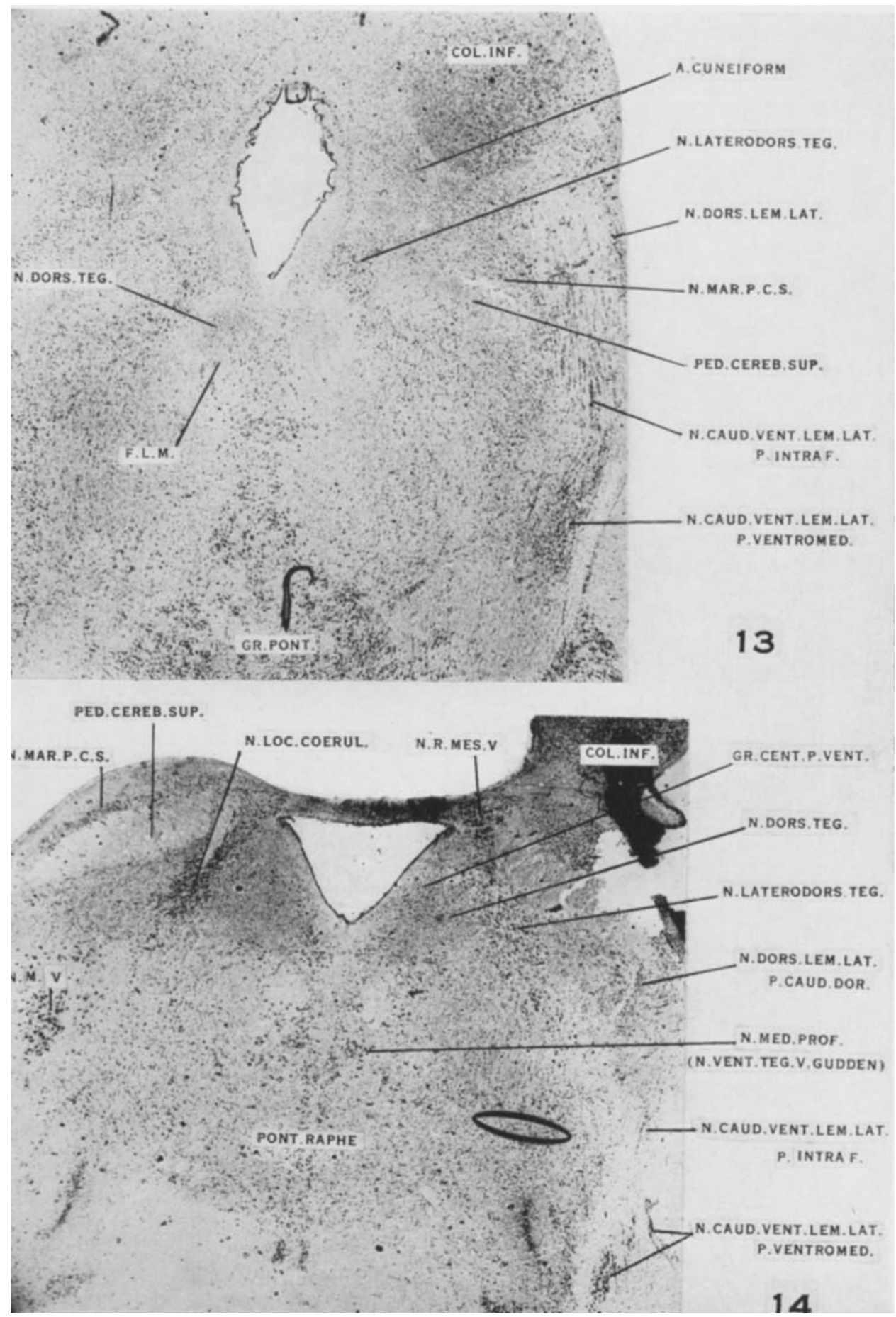




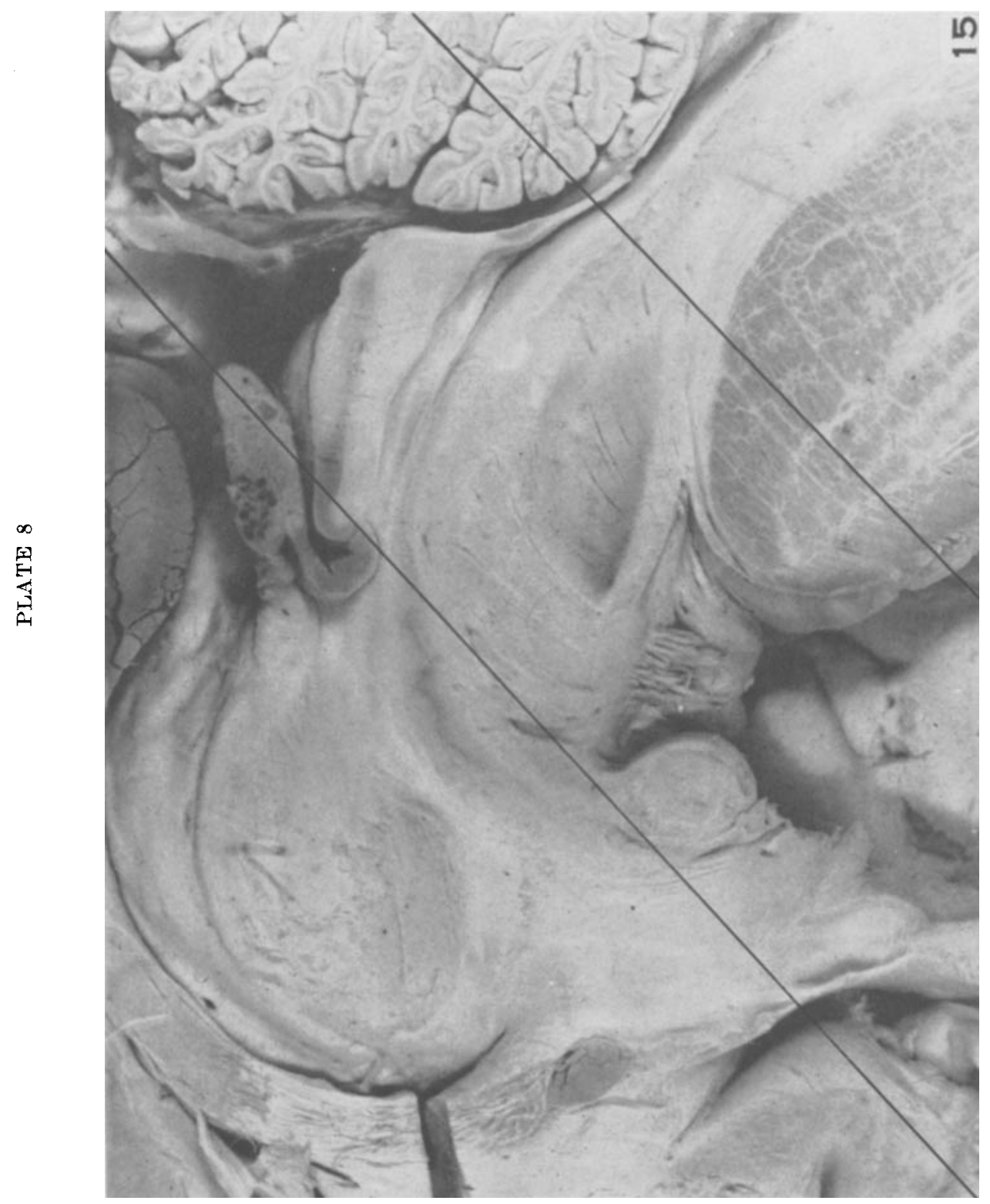




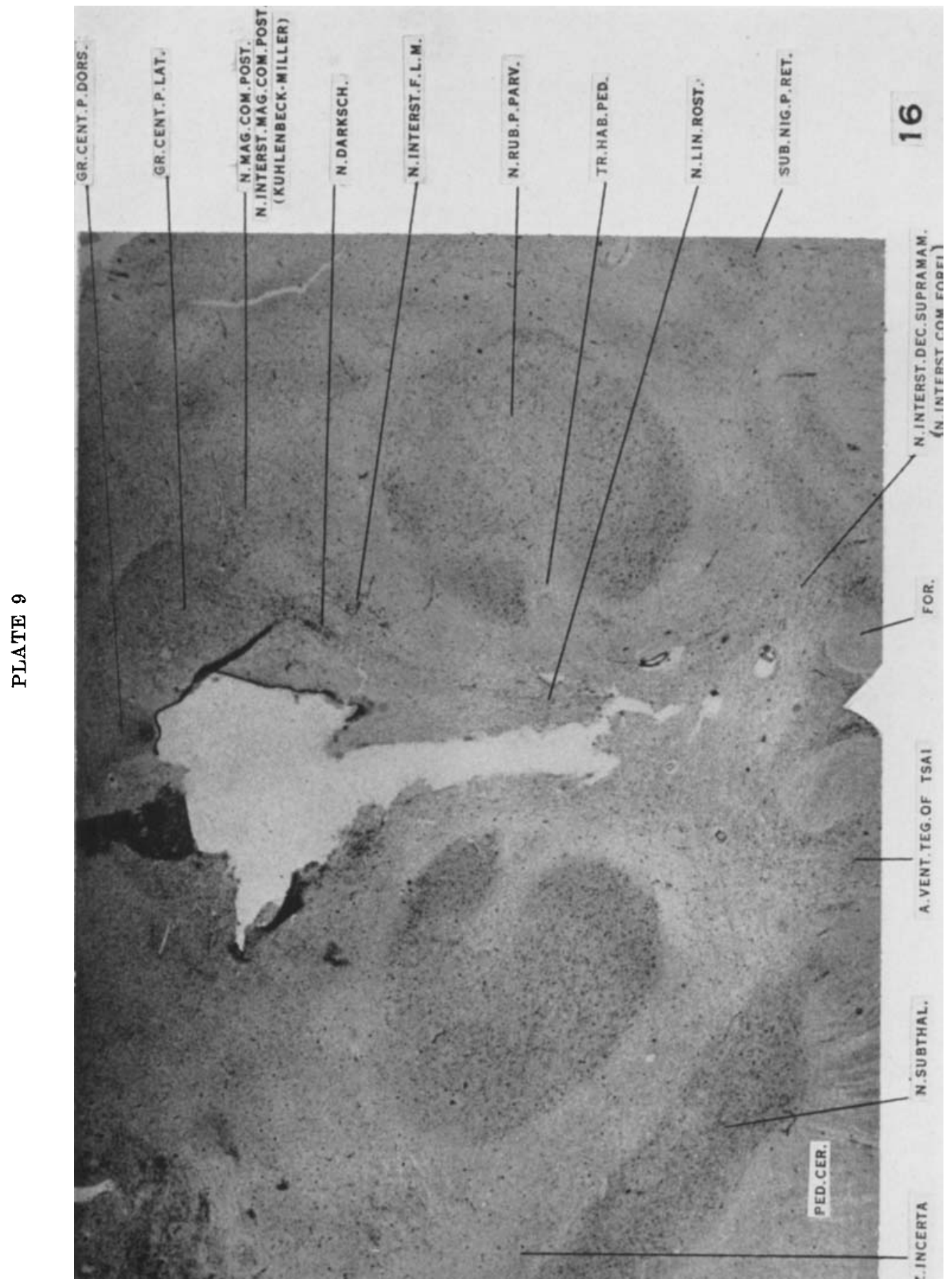




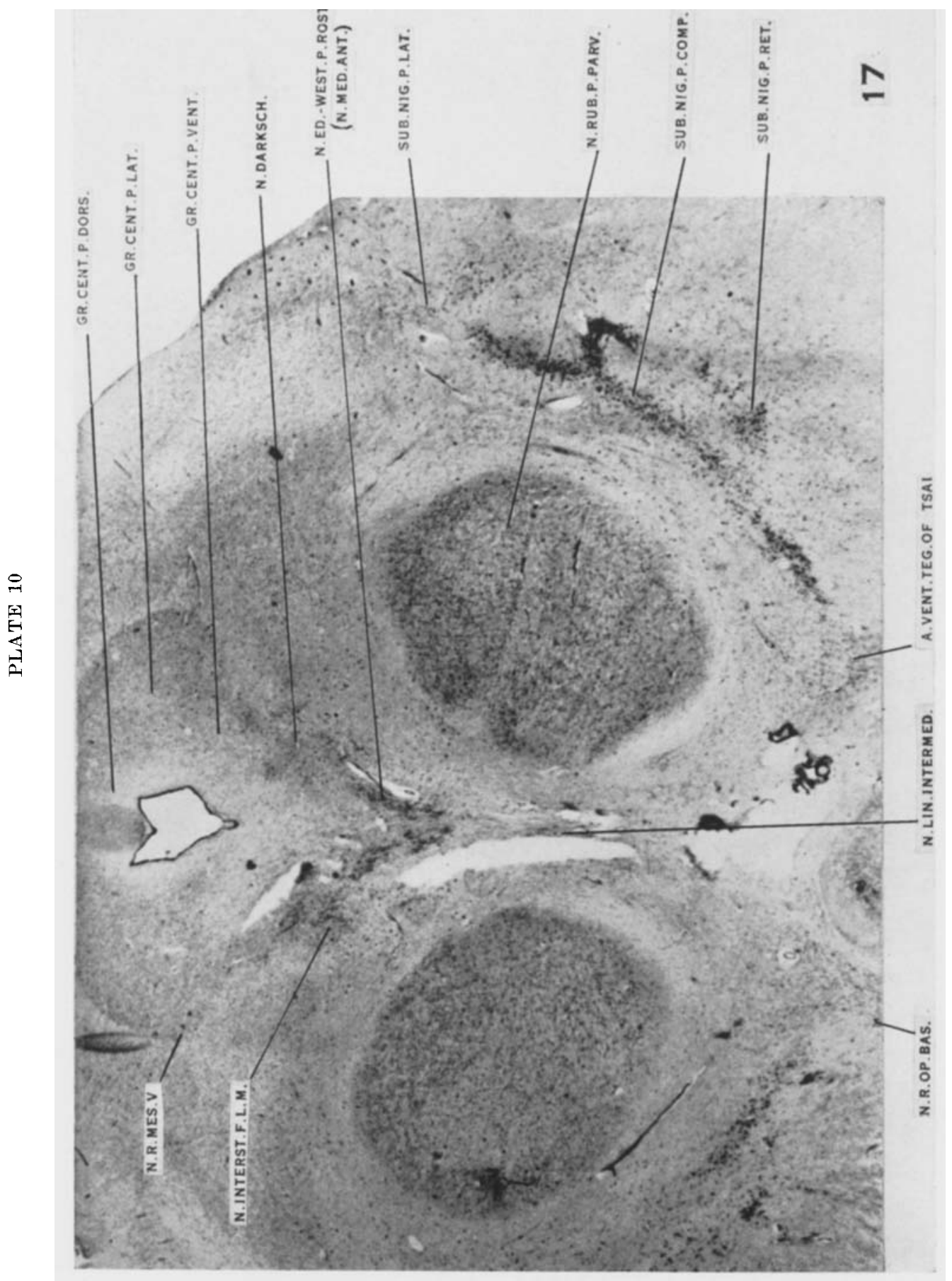




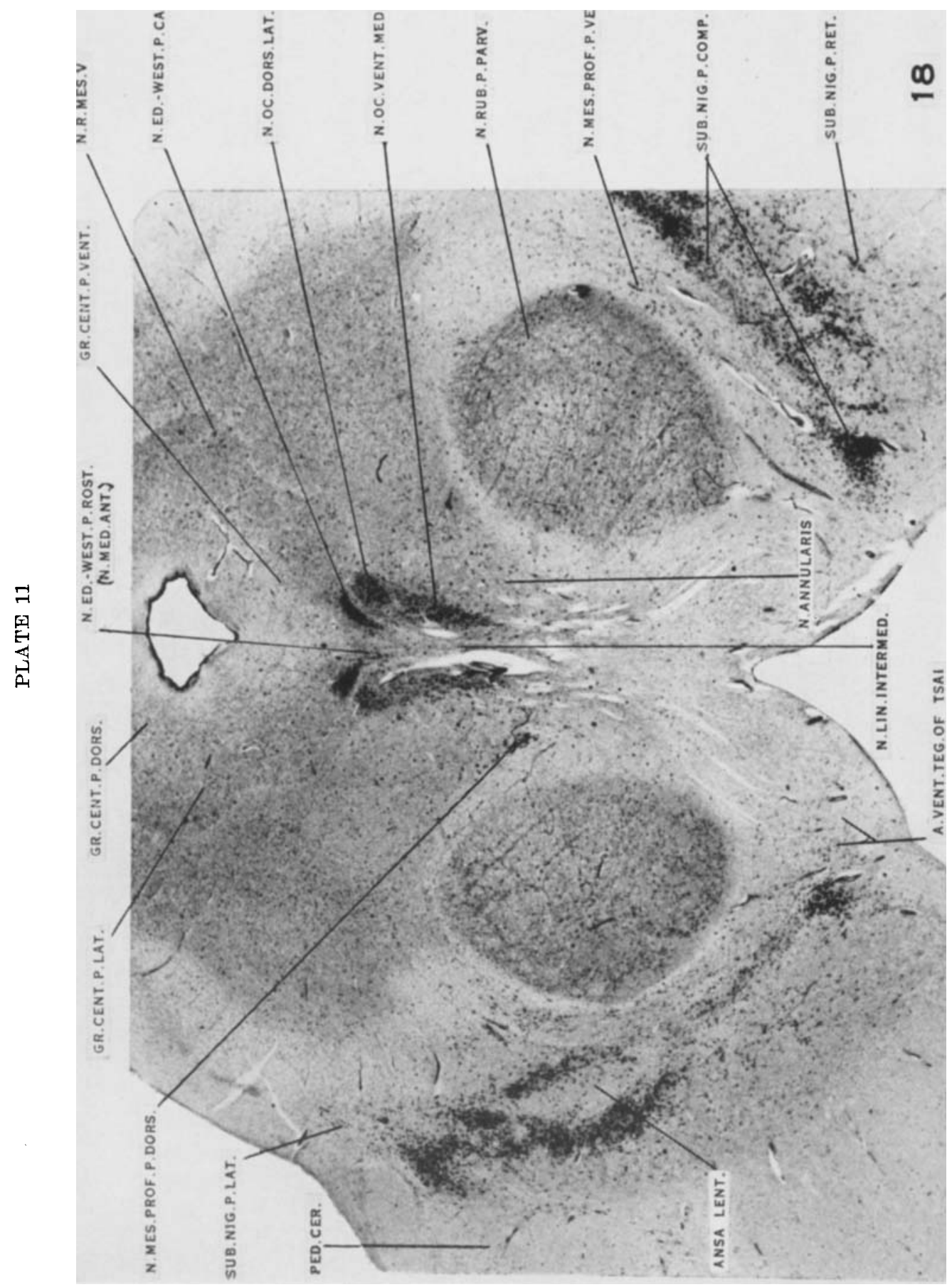




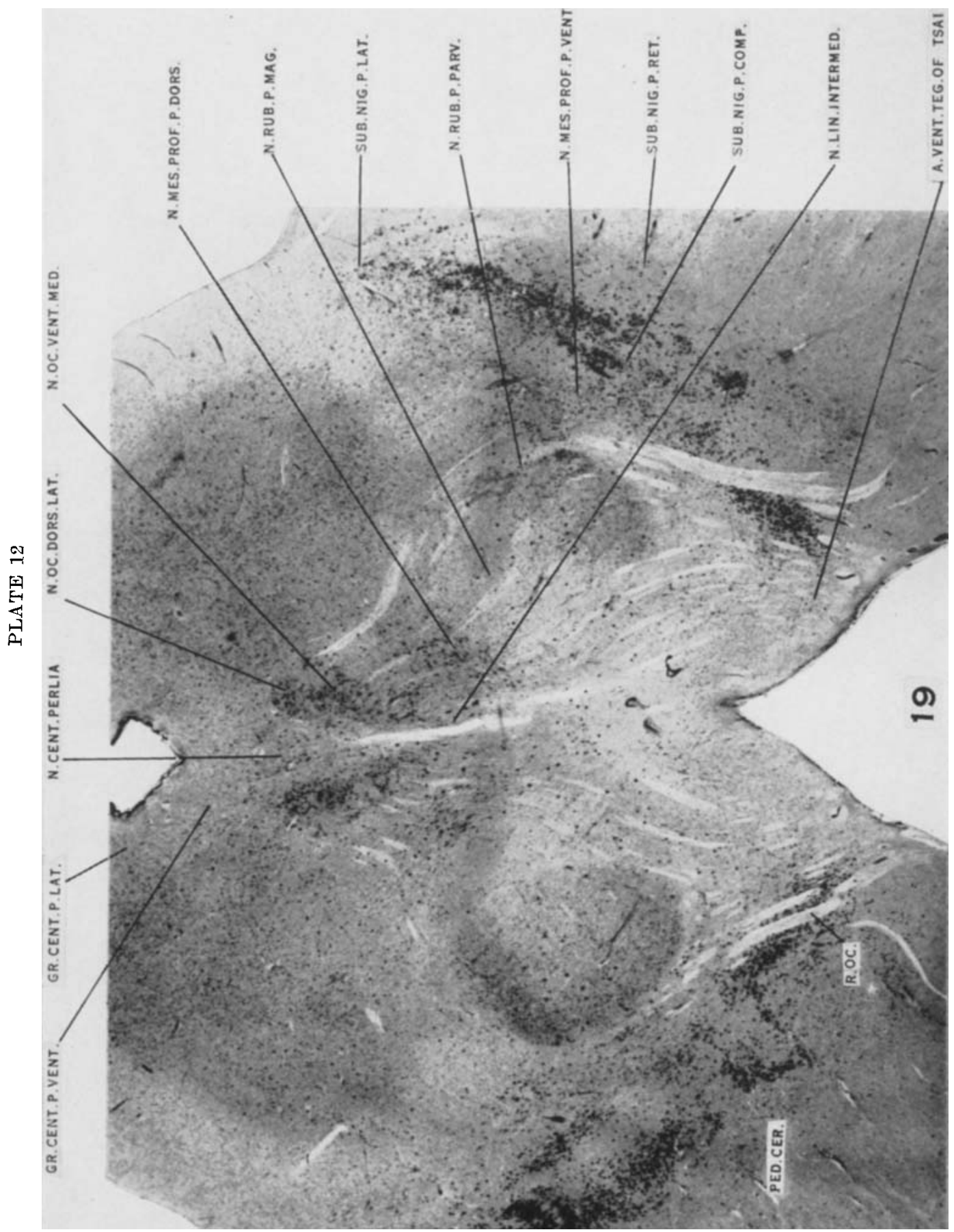


PIATE 13

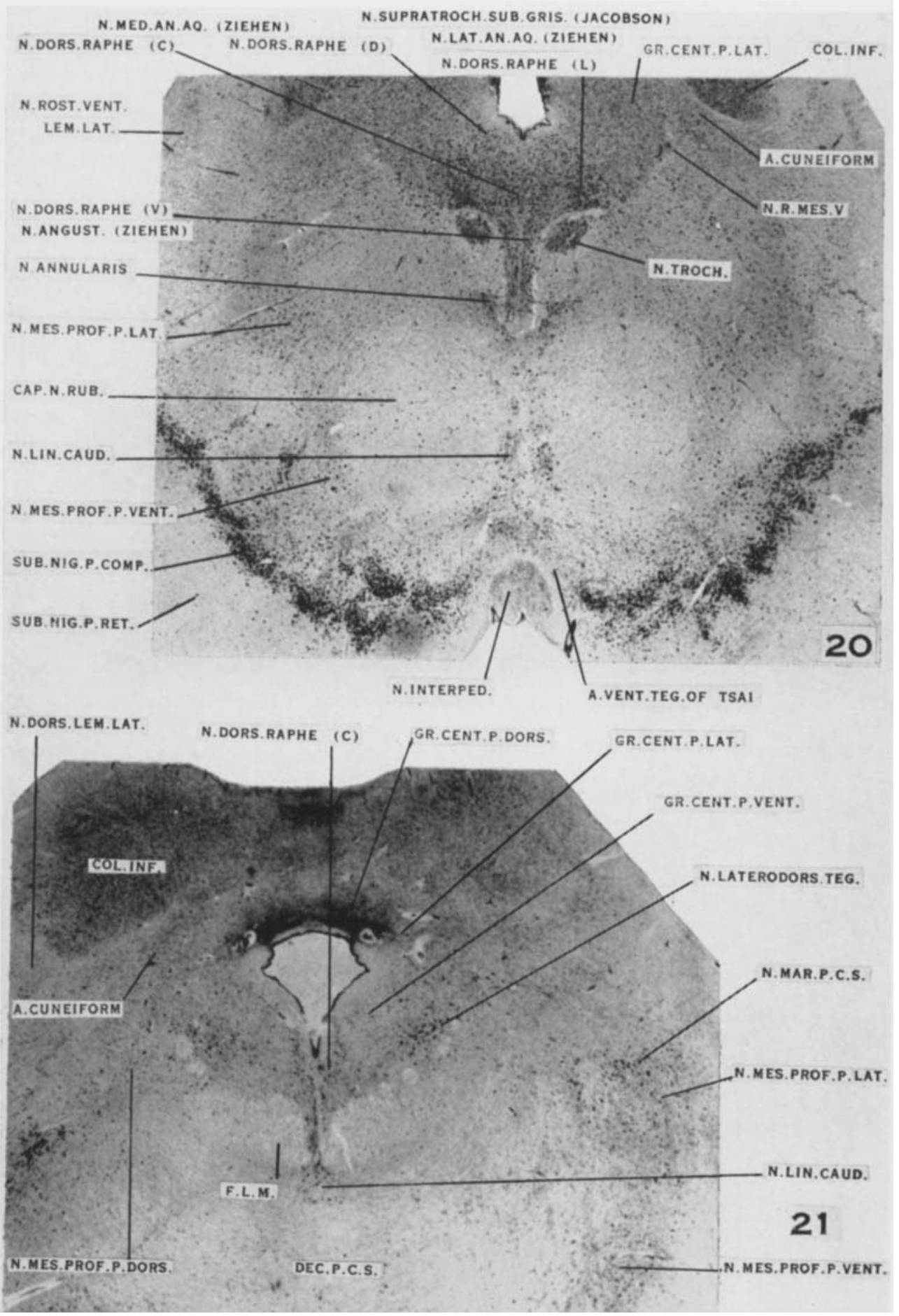


PLATE 14

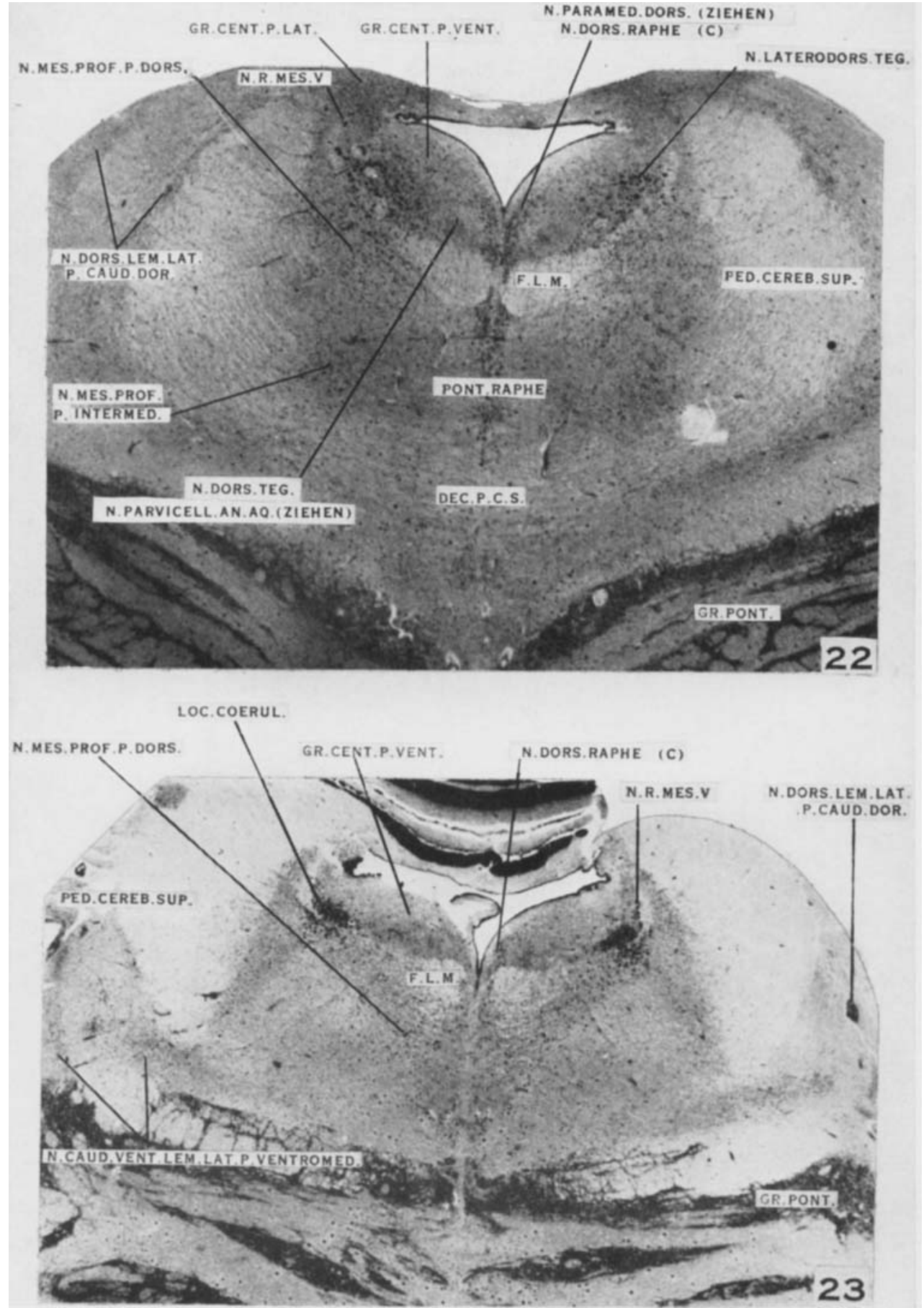

